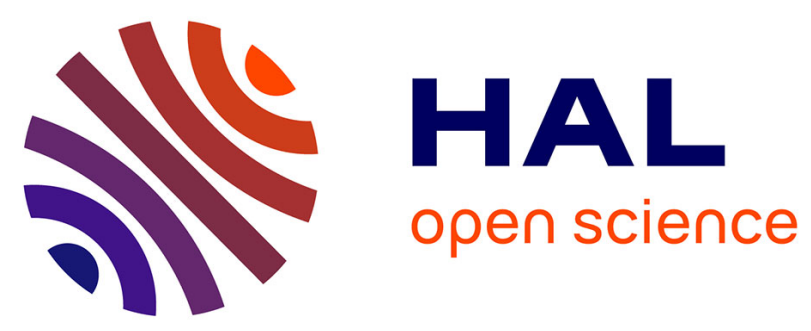

\title{
Evidence of selective activation of aryl hydrocarbon receptor nongenomic calcium signaling by pyrene
}

Bendik C Brinchmann, E. Le Ferrec, William H Bisson, Normand Podechard, Henrik S Huitfeldt, Isabelle Gallais, Odile Sergent, Jørn A Holme, Dominique Lagadic-Gossmann, Johan Øvrevik

\section{To cite this version:}

Bendik C Brinchmann, E. Le Ferrec, William H Bisson, Normand Podechard, Henrik S Huitfeldt, et al.. Evidence of selective activation of aryl hydrocarbon receptor nongenomic calcium signaling by pyrene. Biochemical Pharmacology, 2018, 158, pp.1-12. 10.1016/j.bcp.2018.09.023 . hal-01888873

\section{HAL Id: hal-01888873}

\section{https://hal-univ-rennes1.archives-ouvertes.fr/hal-01888873}

Submitted on 9 Oct 2018

HAL is a multi-disciplinary open access archive for the deposit and dissemination of scientific research documents, whether they are published or not. The documents may come from teaching and research institutions in France or abroad, or from public or private research centers.
L'archive ouverte pluridisciplinaire HAL, est destinée au dépôt et à la diffusion de documents scientifiques de niveau recherche, publiés ou non, émanant des établissements d'enseignement et de recherche français ou étrangers, des laboratoires publics ou privés. 
Title:

\section{Evidence of Selective Activation of Aryl Hydrocarbon Receptor}

\section{Nongenomic Calcium Signaling by Pyrene}

Running title:

\section{Pyrene, AhR, and Calcium Signaling}

Authors:

Bendik C. Brinchmann 1,2*, Eric Le Ferrec ${ }^{3 *}$, William H. Bisson ${ }^{4}$, Norman Podechard ${ }^{3}$, Henrik

S. Huitfeldt5, Isabelle Gallais ${ }^{3}$, Odile Sergent ${ }^{3}$, Jorn A. Holme ${ }^{\#}$, Dominique Lagadic-

Gossmann $^{3 \#, \text { and Johan Øvrevik }}{ }^{1,} \#$

*/\# Equal contribution

Affiliations:

${ }^{1}$ Department of Air Pollution and Noise, Domain of Infection Control, Environment and Health, Norwegian Institute of Public Health, Oslo, Norway.

${ }^{2}$ Division of Laboratory Medicine, Faculty of Medicine, University of Oslo, Oslo, Norway.

${ }^{3}$ Univ Rennes, Inserm, EHESP, Irset (Institut de recherche en santé, environnement et travail) -

UMR_S 1085, F-35000 Rennes, France

${ }^{4}$ Department of Environmental and Molecular Toxicology, Oregon State University, Corvallis,

Oregon, USA

${ }^{5}$ Laboratory for Toxicopathology, Oslo University Hospital, University of Oslo, Oslo, Norway

${ }^{\S}$ Corresponding author: Johan Øvrevik, Department of Air Pollution and Noise, Domain of Infection Control and Environmental Health, Norwegian Institute of Public Health. PO Box 4404 Nydalen, N-0403 Oslo, Norway. E-mail: johan.ovrevik@fhi.no; Phone:+47 21076408

\section{Abstract}

In its classical genomic mode of action, the aryl hydrocarbon receptor (AhR) acts as a ligand activated transcription factor regulating expression of target genes such as CYP1A1 and CYP1B1. Some ligands may also trigger more rapid nongenomic responses through $\mathrm{AhR}$, including calcium signaling $\left(\mathrm{Ca}^{2+}\right)$. In the present study we observed that pyrene induced a relatively rapid increase in intracellular 
$\mathrm{Ca}^{2+}$-concentrations $\left(\left[\mathrm{Ca}^{2+}\right]_{i}\right)$ in human microvascular endothelial cells (HMEC-1) and human embryonic kidney cells (HEK293) that was attenuated by AhR-inhibitor treatment and/or transient AhR knockdown by RNAi. In silico molecular docking based on homology models, suggested that pyrene is not able to bind to the human AhR in the agonist conformation. Instead, pyrene docked in in the antagonist conformation of the the AhR PAS-B binding pocket, although the interaction differed from antagonists such as GNF-351 and CH223191. Accordingly, pyrene did not induce CYP1A1 or CYP1B1, but suppressed CYP1-expression by benzo $[a]$ pyrene $(\mathrm{B}[a] \mathrm{P})$ in HMEC-1 cells, confirming that pyrene act as an antagonist of AhR-induced gene expression. Use of pharmacological inhibitors and $\mathrm{Ca}^{2+}$-free medium indicated that the pyrene-induced $\mathrm{AhR}$ nongenomic $\left[\mathrm{Ca}^{2+}\right]_{i}$ increase was initiated by $\mathrm{Ca}^{2+}$-release from intracellular stores followed by a later phase of extracellular $\mathrm{Ca}^{2+}$ influx, consistent with store operated calcium entry (SOCE). These effects was accompanied by an AhR-dependent reduction in ordered membrane lipid domains, as determined by di-4-ANEPPDHQ staining. Addition of cholesterol inhibited both the pyrene-induced $\left[\mathrm{Ca}^{2+}\right]_{i}$-increase and alterations in membrane lipid order. In conclusion, we propose that pyrene binds to AhR, act as an antagonist of the canonical genomic AhR/Arnt/CYP1-pathway, reduces ordered membrane lipid domains, and activates AhR nongenomic $\mathrm{Ca}^{2+}$-signaling from intracellular stores.

Keywords: Polycyclic aromatic hydrocarbons, aryl hydrocarbon receptor, calcium, endothelial cells, membrane remodelling

\section{Introduction}

The aryl hydrocarbon receptor (AhR), which is a basic helix-loop-helix PAS transcription factor, plays a central role in regulating toxicity from PAHs. In its classical mode of action, ligand-activated AhR translocates to the nucleus and dimerizes with the AhR nuclear translocator (Arnt). The AhRArnt complex then binds to so-called dioxin or xenobiotic response elements (DREs or XREs) in the promotor region of target genes. The prototypical genes activated by AhR are the cytochrome $\mathrm{P} 450$ 
enzymes CYP1A1 and CYP1B1, but AhR also regulates a number of other genes including many central proinflammatory mediators $(1,2)$. Notably, AhR-signaling is highly ligand specific and not restricted to the classical mode of action $(3,4)$. Nonclassical AhR-signaling involves crosstalk with a number of other transcription factors and signaling molecules independently of Arnt activation (24). In addition, it has been suggested that many of the toxic effects of the AhR ligand 2,3,7,8tetrachlorodibenzodioxin (TCDD) could be due to nongenomic AhR-signaling where the receptor rather functions as a signaling molecule in the cytosol (1). As such, the emerging pattern of AhR signaling is strikingly similar to the signaling from a number of nuclear receptors, including estrogen receptor (ER), which also involves both genomic and nongenomic modes of action (5).

As for ER-signaling, AhR nongenomic responses appear to involve both activation of protein kinases as well as mediation of calcium $\left(\mathrm{Ca}^{2+}\right)$ responses within min after exposure, hence preceding the genomic activation of target genes $(1,3,5)$. These early cytosolic responses of the AhR are far less understood than the genomic mode of action and have predominately been investigated for TCDD. It is therefore unclear whether genomic and nongenomic signaling is triggered simultaneously through interaction with the same motifs within the AhR-PAS-B binding pocket, or whether the rank order of ligand potencies could differ for induction of genomic and nongenomic signaling.

Polycyclic aromatic hydrocarbons (PAHs) constitute a central group of AhR ligands originating from incomplete combustion of organic materials. The main toxicological concern has historically been carcinogenic effects, and CYP1A1/CYP1B1is central in the metabolic activation and subsequent mutagenic effects of several PAHs (6). In risk assessment the toxicity of PAHs has been converted into toxicity equivalency factors (TEFs) based on estimates of relative carcinogenicity compared to the known human carcinogen benzo $[a]$ pyrene $(\mathrm{B}[a] \mathrm{P})(7)$. Pyrene is among the most abundant PAHs in outdoor air occurring at concentrations that are orders of magnitudes higher than $\mathrm{B}[a] \mathrm{P}(8)$, but is not classifiable as carcinogen to humans (IARC group 3 compound), and has a very low TEF value 
of 0.001 (7). However, pyrene exposure has been associated with asthma in children (9) and cardiovascular disease (10). Studies in zebrafish embryos suggest that pyrene may induce peripheral vascular defects, cardiotoxicity and neuronal cell death (11-13). Moreover, pyrene and its derivatives, but not $\mathrm{B}[a] \mathrm{P}$ or $\beta$-naphthoflavone, potentiate pro-inflammatory responses induced by a toll-like receptor-3 ligand (14). This suggests that pyrene triggers some effects that are distinctly different from $\mathrm{B}[a] \mathrm{P}$.

The reported lack of effect on CYP1A1/CYP1B1expression in human cells suggest that pyrene may have limited ability to bind and activate AhR (15-17). In contrast, it appears that pyrene induce CYPexpression in fish and rats, although with considerable lower potency than $\mathrm{B}[a] \mathrm{P}(18-20)$, and it has been suggested that developmental toxicity of pyrene in zebrafish is mediated through AhRdependent mechanisms due to qualitative similarities with effects from TCDD (11). Studies from our lab have shown that the nitro-derivative 1-nitropyrene is capable of inducing CYP1A1 expression in rat Hepa1c1c7 cells, but fails to do so in human bronchial epithelial BEAS-2B cells $(21,22)$. This could be due to differences in ligand selectivity and gene regulation between the human AhR and AhR from other species (23-25). One possibility is that pyrene and pyrene derivatives could bind the human AhR, but fail to induce the classical genomic signaling.

Previous studies from our consortium have shown that pyrene induces a relatively rapid increase in $\left[\mathrm{Ca}^{2+}\right]_{i}$ in human microvascular endothelial HMEC-1 cells, almost twice the magnitude of calcium responses induced by $\mathrm{B}[a] \mathrm{P}$ and other PAHs investigated (16). In the present study we have explored the mechanism of pyrene-induced increase in $\left[\mathrm{Ca}^{2+}\right]_{i}$ in $\mathrm{HMEC}-1$ cells. Our results suggest that pyrene is a AhR ligand that may selectively activate nongenomic signaling, triggering increase in $\left[\mathrm{Ca}^{2+}\right]_{i}$ through store-operated calcium entry (SOCE) in parallel with alteration in membrane organization in HMEC-1 cells. This strongly supports the notion that pyrene may have unique 
toxicological effects, and shows that AhR nongenomic signaling may be triggered independently of the classical genomic pathway.

\section{Materials and methods:}

\subsection{Chemicals}

Benzo[a]pyrene (B[a]P), pyrene, 2-methyl-2H-pyrazole-3-carboxylic acid (2-methyl-4-o-tolylazophenyl)-amide (CH223191), cholesterol, hydrocortisone and EGTA were purchased from SigmaAldrich (St. Louis, MO, USA; now Merck). TRIzol® reagent, pluronic acid and Fura-2 acetoxymethylester (Fura-2-AM) were provided by InVitrogen (Carlsbad, CA, USA). 1-[2-(4Methoxyphenyl)-2-[3-(4-methoxyphenyl)propoxy]ethyl-1H-imidazole hydrochloride (SKF 96365) and $\quad \mathrm{N}-[4-[3,5-B i s($ trifluoromethyl)-1H-pyrazol-1-yl]phenyl]-4-methyl-1,2,3-thiadiazole-5carboxamide (BtP2) was obtained from TOCRIS (Bristol, UK). 2-Aminoethoxydiphenylborate (2APB) was purchased from Merck Millipore (Burlington, MA, USA. Di-4ANEPPDHQ, MCDB 131 medium, and L-glutamine (200 mM) were purchased from Thermo Fischer Scientific (Carlsbad, CA, USA). Fetal bovine serum (FBS) by Biochrom AG (Berlin, Germany), and endothelial growth factor by Nerliens Meszansky (Oslo, Norway). Penicillin and streptomycin were from Lonza (Walkersville, MD, USA). All real-time RT-PCR reagents and TaqMan probes/primers were purchased from Applied Biosystems (Foster City, CA, USA). All other reagents were commercial products of the highest purity available.

\subsection{Cell culture}

Human endothelial HMEC-1 cells, obtained from ATCC through LGC Standards (Wesel, Germany) were routinely maintained in MCDB 131 medium containing epidermal growth factor $(10 \mathrm{ng} / \mathrm{mL})$, hydrocortisone $(1 \mu \mathrm{g} / \mathrm{mL})$, penicillin $(50 \mathrm{unit} / \mathrm{mL})$, and streptomycin $(50 \mu \mathrm{g} / \mathrm{mL})$ and supplemented with $10 \%$ FBS, according to the providers' instructions. Experiments were performed on HMEC-1 cells at passage numbers 22-32. Human embryonic kidney HEK293 cells were maintained in 
Dulbecco's modified Eagle's medium containing penicillin (50 unit/mL), and streptomycin (50 $\mu \mathrm{g} / \mathrm{mL}$ ) and supplemented with 10\% FBS. The HEK293 cells was a gift from the late Hervé Paris, INSERM, Toulouse, France. The passage number of and origin of these cells, that was used in a limited number of experiments are not known. HEK293 cells permanently expressing $\beta 1-/ \beta 2 A D R$ were obtained by $\beta 1-/ \beta 2 A D R$ cDNA transfection using Lipofectamine (Invitrogen) as described elsewhere (26). Chemicals were commonly prepared as stock solution in dimethyl sulfoxide (DMSO). The final concentration of solvent did not exceed $0.2 \%(\mathrm{v} / \mathrm{v})$; control cultures received similar concentration of DMSO.

Cells used for $\mathrm{Ca}^{2+}$ measurements or fluorescence measurements of membrane order were grown on glass coverslips to $50-60 \%$ confluency and serum starved for a minimum of $12 \mathrm{~h}$ prior to exposure. The glass coverslips were sterilized in ethanol of increasing concentrations from $70-99 \%$, and then coated with serum proteins using pure FBS prior to cell culture. Cells used for q-PCR were cultivated in 6-well plates, grown to near confluence and serum starved for a minimum of $12 \mathrm{~h}$ prior to exposure.

\subsection{Calcium measurements}

HMEC-1 were grown on glass lamellas to $50-60 \%$ confluency and serum starved for a minimum of $12 \mathrm{~h}$ prior to exposure. Before exposure cells were mounted in exposure chambers containing $1 \mathrm{~mL}$ cell suspension buffer. Calcium cell suspension buffer contained: $134.8 \mathrm{mM} \mathrm{NaCl}, 4.7 \mathrm{mM} \mathrm{KCl,} 1.2$ mM K2HPO4, $1 \mathrm{mM} \mathrm{MgCl2,} 1 \mathrm{mM} \mathrm{CaCl2,} 10 \mathrm{mM}$ glucose, $10 \mathrm{mM}$ HEPES, pH 7.4. Cells were washed two times with the buffer before loading with Fura-2AM for $30 \mathrm{~min}$. Inhibitors were added during this loading period, and after the loading buffer had been washed off. Calcium-free cell suspension buffer containing the extracellular calcium chelator ethylene glycol tetra acetic acid (EGTA) was used after loading in experiments on extracellular $\mathrm{Ca}^{2+}$ dependency. Variations in intracellular $\mathrm{Ca}^{2+}$ concentrations $\left[\mathrm{Ca}^{2+}\right]_{i}$ were analysed in HMEC-1 cells exposed to all four DEPOE, by micro-spectrofluorometry using the $\mathrm{Ca} 2+$ sensitive probe Fura-2AM, as previously reported 
(27). Briefly, cells were incubated at $37^{\circ} \mathrm{C}$ in cell suspension buffer supplemented with $1.5 \mu \mathrm{M}$ Fura2AM and $0.006 \%$ pluronic acid. After 30 min loading, cells were washed two times with the buffer before exposure. The $\left[\mathrm{Ca}^{2+}\right]_{i}$ imaging involved data acquisition every $10 \mathrm{~s}$ (emission at $510 \mathrm{~nm}$ ) at 340- and 380-nm excitation wavelengths using an LEICA DMIRB microscope with an inverse 40x oil objective. We monitored changes in $\left[\mathrm{Ca}^{2+}\right]_{i}$ using an imaging system equipped with a Retiga 1300I fast-cooled monochromatic digital camera (12-bit) (Qimaging, Burnaby, BC, Canada), and a monochromator for fluorophore excitation. Image acquisition and analysis, involving determination of pixels assigned to each cell, was performed with METAFLUOR software (Universal Imaging, Downingtown, PA, USA). Average pixel value for each cell, was obtained with excitation at both wavelengths and corrected for background. We obtained the ratio by dividing the $340-\mathrm{nm}$ by the 380 $\mathrm{nm}$ fluorescence image on a pixel-by-pixel base $(\mathrm{R}=\mathrm{F} 340 \mathrm{~nm} / \mathrm{F} 380 \mathrm{~nm}$. Results are presented as normalized calcium level compared to basal $\left[\mathrm{Ca}^{2+}\right]_{i}$ measured 3 min prior to exposure. Area under the curve (AUC) was calculated from baseline (1.0).

\subsection{Determination of structural perturbation of plasma membrane}

Plasma membrane-order was visualized by confocal fluorescence microscopy using the membrane order sensitive di-4 ANEPPDHQ probe. This probe displays a fluorescent spectral blue-shift from $620 \mathrm{~nm}$ when incorporated into membranes with a low lipid order (in a liquid disordered phase, Ld) to $560 \mathrm{~nm}$ when inserted into membranes with a high lipid order (in a liquid-ordered phase, Lo). After acquisition using confocal fluorescence microscopy of both disordered and ordered-phase fluorescence images, a new image, indicative of membrane lipid order, was obtained by calculating the generalized polarization (GP) value, a ratiometric measurement of fluorescence intensities for each pixel which is correlated to membrane lipid order (28). Briefly, after each treatment, HMEC-1 cells grown on glass coverslips were washed in phosphate buffer saline (PBS) and then fixed in 4\% paraformaldehyde in PBS at $4{ }^{\circ} \mathrm{C}$. After three washes in PBS, the cells were stained with $5 \mu \mathrm{M}$ di-4 
ANEPPDHQ for $90 \mathrm{~min}$ and washed twice in PBS. Cells were then visualized with confocal fluorescence microscope LEICA DMI 6000 CS (Leica Microsystems, Wetzlar, Germany). Under excitation at $488 \mathrm{~nm}$ with an argon ion laser, ordered membrane images were acquired with a photomultiplier tube (PMT) range of 500 to $580 \mathrm{~nm}$ whereas for disordered membrane images, the PMT range was 620 to $750 \mathrm{~nm}$ (magnification $\mathrm{x}$ 400). Using Fiji imaging processing software (ImageJ; National Institutes of Health, Bethesda, USA) and the macro published by Owen et al. (28), GP images were generated according to the following calculation: $\mathrm{GP}=\left(\mathrm{I}_{500-580}-\mathrm{I}_{620-750}\right) /\left(\mathrm{I}_{500-580}\right.$ $+\mathrm{I}_{620-750}$ ). On each GP image generated (containing usually between 1 to 3 cells), a GP values was measured and normalized by subtraction of the mean of all GP values found for DMSO-treated cells ( $\triangle \mathrm{GP}$ values). Then, $\Delta \mathrm{GP}$ values of images from at least 3 experiments were used to generate a dot blot. Finally, the global mean of $\Delta \mathrm{GP}$ values for each condition was calculated from a minimum of 10 images.

Changes in bulk membrane fluidity were explored by electron paramagnetic resonance (EPR) spectroscopy using paramagnetic reporter groups incorporated into the membrane, as previously described (29). Membranes were spin labelled by incubating cell suspensions at $37{ }^{\circ} \mathrm{C}$ for $15 \mathrm{~min}$ with 12-doxyl stearic acid $(50 \mu \mathrm{g} / \mathrm{mL})$. The EPR spectra of labelled samples were acquired at an ambient temperature on a Bruker Elexsys EPR spectrometer operating at $3509 \mathrm{G}$ center field, $20 \mathrm{~mW}$ microwave power, 9.86-GHz microwave frequency, $1.77 \mathrm{G}$ modulation amplitude and $100 \mathrm{kHz}$ modulation frequency. The fluidity of the labelled membranes was quantified by calculating the order parameter S, which is inversely related to membrane fluidity.

\subsection{Immunocytochemical staining and fluorescence microscopy}

Cell cultures were fixed with 4\% paraformaldehyde in PBS for $10 \mathrm{~min}$, washed in PBS for $10 \mathrm{~min}$, briefly dipped in $\mathrm{H} 2 \mathrm{O}$, and dried. Fixed cells were incubated with rabbit anti-Ahr (Santa Cruz Biotechnology, Dallas, Texas, USA) diluted (1:100) in PBS with 1\% BSA for $20 \mathrm{~h}$, followed by 2 X10 
min washes in PBS, a brief dip in $\mathrm{H}_{2} \mathrm{O}$, and dried. The cells were then exposed to Alexa488conjugated donkey anti-rabbit IgG (1:200, Jackson Immunoresearch, West Grove, PA, USA) for one h, and washed 2 X10 min in PBS, briefly dipped in $\mathrm{H}_{2} \mathrm{O}$, dried, and mounted with Dako Fluorescent Mounting Medium (Dako Denmark A/S, Glostrup, Denmark). Hoechst dye (H33254, 0.05ug/ml was added to the last washing buffer. A Leica DMRE fluorescence microscope equipped with A and L5 fluorescence filter cubes were used for observations. An F-view CD camera and Analysis 3.1 software (Olympus, Tokyo, Japan) were used for documentation.

\subsection{Gene silencing by RNA interference}

HMEC-1 cells were transiently transfected with ON-TARGETplus SMARTpool siRNAs against AhR, or ON-TARGETplus non-targeting (NT) control siRNAs (Dharmacon, Chicago, IL; USA). Briefly described, semi-confluent cells were transfected with 100 nM siRNAs using Dharmafect-1 transfection reagent diluted in antibiotic-free culture medium, as previously described (16). Fortyeight $\mathrm{h}$ after transfection, cells were exposed to pyrene and analysed for effects on $\mathrm{Ca}^{2+}$-signaling.

\subsection{Gene expression analysis by real-time PCR}

Total RNA was isolated using NucleoSpin RNA Plus (Macherey-Nagel; Düren, Germany) and reverse transcribed to cDNA on a PCR System 2400 (PerkinElmer, Waltham, MA, USA) using a High Capacity cDNA Archive Kit (Applied Biosystems, Foster City, CA, USA). Real-time PCR was performed using pre-designed TaqMan Gene Expression Assays and TaqMan Universal PCR Master Mix and run on ABI 7500 fast (Applied Biosystems). Gene expression of CYP1A1 (Hs00153120_m1) and CYP1B1 (Hs02382916_s1) were normalized against GAPDH (Hs02758991_g1), and expressed as fold change compared to untreated control as calculated by the $\Delta \Delta \mathrm{Ct}$ method $(\Delta \mathrm{Ct}=\mathrm{Ct}[\mathrm{Gene}$ of Interest $]-\mathrm{Ct}[18 \mathrm{~S}] ; \Delta \Delta \mathrm{Ct}=\Delta \mathrm{Ct}[$ Treated $]-\Delta \mathrm{Ct}[\mathrm{Control}] ;$ Fold change $=2[-\Delta \Delta \mathrm{Ct}])$

\subsection{In silico molecular modelling and docking}


The homology models of the human AhR-PAS-B in the agonist and antagonist conformation were built and refined as previously described by Bisson and colleagues (30). Molecular Docking was run as reported elsewhere (30). The ICM program relies on global optimization of the entire flexible ligand in the receptor field and combines large-scale random moves of several types with gradient local minimization and a search history mechanism. In the ICM-VLS (Molsoft ICM) screening procedure, the scoring function should give a good approximation of the binding free energy between a ligand and a receptor, and its usually a function of different energy terms based on a force-field (31). The lower the ICM score, the higher the chance the ligand is a binder.

\subsection{Statistical analysis}

Statistical analyses were performed by ANOVA with Holm-Sidak post-test for multiple comparisons. Threshold for statistical significance was set at $\mathrm{P}>0.05$. The gene expression data were analyzed using the $\triangle \mathrm{CT}$-values from the q-PCR measurements. All calculations were based on analysis of independent experiments (biological replicates), with exception of the membrane-order measurements by confocal microscopy. Due the inherent variability in di-4-ANEPPDHQ-staining among individual cells, a very high counting-number is needed to obtain statistical significance. The statistical analysis was therefore based on pooled technical replicates from three or more independent experiments. All calculations were performed with GraphPad Prism 6 software (GraphPad Software, Inc., San Diego, CA).

\section{Results}

\subsection{Pyrene triggers a transient increase of intracellular calcium concentration in HMEC-1 cells}

We first assessed the effects of pyrene on calcium signaling in human microvascular HMEC-1 cells. Briefly, cells were incubated with the calcium sensitive fluorescent probe Fura-2-AM, and alterations in calcium signaling were recorded by continuous microscopy imaging. Three min after recordings started, cells were exposed to $1 \mu \mathrm{M}$ Pyrene. As seen in Figure 1, pyrene induced a relatively rapid 
and substantial increase in $\left[\mathrm{Ca}^{2+}\right]_{i}$ in HMEC-1 cells, as compared to DMSO. No visual sign of toxicity was observed during the exposure period (not quantified). Moreover, the pyrene-triggered increase in $\left[\mathrm{Ca}^{2+}\right]_{\mathrm{i}}$ declined towards resting state within one $\mathrm{h}$ (Fig 1, insert graph). Thus the observed $\left[\mathrm{Ca}^{2+}\right]_{i^{-}}$ response did not seem to result from unspecific cytotoxicity.

\subsection{Pyrene induces $\left[\mathrm{Ca}^{2+}\right]_{i}$ increase through AhR-dependent mechanisms}

To investigate the potential role of AhR-dependent in regulation $\mathrm{Ca}^{2+}$-responses, HMEC-1 cells were pre-incubated with CH223191, a well-known AhR antagonist, prior to pyrene exposure. As shown in figure 2A, CH223191 treatment abrogated the $\mathrm{Ca}^{2+}$-response induced by pyrene. Transfection of HMEC-1 cells with siRNA against AhR also attenuated the pyrene-induced $\left[\mathrm{Ca}^{2+}\right]_{\mathrm{i}}$-response as compared to cells transfected with non-targeting siRNA (Fig. 2B). Moreover, pyrene triggered a similar increase in $\left[\mathrm{Ca}^{2+}\right]_{i}$ in HEK293 cells that could also be abrogated by CH223191 treatment (Fig. 2C). This suggest that AhR was essential for the pyrene-induced increase in $\left[\mathrm{Ca}^{2+}\right]_{i}$, and that this AhR-dependent response was not restricted to HMEC-1 cells.

\subsection{Pyrene docks in the AhR antagonist conformation in silico}

The possible interaction between pyrene and AhR was assessed by in silico molecular docking based on homology models. The AhR agonists TCDD and $\mathrm{B}[a] \mathrm{P}$, the AhR antagonists GNF-351 and CH223191, as well as pyrene were first docked into a model of the human AhR-PAS-B binding pocket in the agonist conformation. TCDD docked with the highest score, establishing a dual hydrogen bond interaction with the side chain of Ser 88/Ser 365 and His 14/His 291 (Fig. 3A, Table 1). $\mathrm{B}[a] \mathrm{P}$ docked with a lower score of -6.8 (Fig. 3B, Table 1), which remains above the threshold value of -5.314 , previously calculated with this model, for predicting AhR agonist activity (30). Based on this threshold value, both antagonists and pyrene were not predicted being agonists of the human AhR (Table 1). 
The AhR antagonists GNF-351 and CH223191, as well as pyrene, were then docked into the human AhR-PAS-B binding pocket in the antagonist conformation. GNF-351 docked with the highest score of -35.14 , establishing two hydrogen-bond interactions with the side chain of Gln106/Gln 383 and the backbone carbonyl of Gly 42/Gly 321 (Fig. 4A, Table 2). The antagonist CH223191 docked with a lower score of -25.73 , and similarly to GNF-351, favouring a hydrogen bond interaction with the side chain of Gln106/Gln 383 (Fig. 4B, Table 2). Pyrene docked with the lowest score of -19.79 and without non-covalent bindings involved (Fig. 4C, Table 2). Interestingly, the score and the strength of interaction between the ligand and residue Gln 106/ Gln 383, highly correlate with the ranking of AhR binding, going from nanomolar (GNF-351), to low- (CH223191) and high- (pyrene) micromolar range. Moreover, as shown in Figure 4A-B, there is high probability of contact between residues Phe 47/ Phe 324 - Ile 48/ Ile 325 of the AhR and the indole and tolylazo-phenyl groups of GNF-351 and CH223191, respectively. In the case of pyrene, the number of possible contacts between the ligand and the two residues are not significant (Fig. 4C). Thus, the in silico modelling suggest that pyrene may act as a ligand for the AhR. However its docking into the AhR-PAS-B binding pocket differs from both "classical" agonists such as TCDD and $\mathrm{B}[a] \mathrm{P}$, as well as the two antagonists GNF-351 and CH223191.

\subsection{Reciprocal antagonism between pyrene-induced $\left[\mathrm{Ca}^{2+}\right]_{i}$ and $B[a] P$-induced $\mathrm{CYP} 1 \mathrm{A1} / \mathrm{CYP} 1 \mathrm{~B} 1$}

To further explore the nature of AhR-involvement in pyrene-induced $\left[\mathrm{Ca}^{2+}\right]_{i}$, we examined effects of combinatory exposure with $\mathrm{B}[a] \mathrm{P} . \mathrm{B}[a] \mathrm{P}$ is a well-known inducer of the prototypical markers of $\mathrm{AhR}$ genomic signaling, CYP1A1 and CYP1B1. Thus, HMEC-1 cells were exposed to either pyrene or $\mathrm{B}[a] \mathrm{P}$, or the two PAHs in combination for $15 \mathrm{~min}$. In line with previous observations (16), pyrene induced a considerably stronger $\left[\mathrm{Ca}^{2+}\right]_{i}$ response, compared to $\mathrm{B}[a] \mathrm{P}($ Fig. $5 \mathrm{~A}) . \mathrm{B}[a] \mathrm{P}$ also induced a slower increase in $\left[\mathrm{Ca}^{2+}\right]_{i}$ in HMEC-1 cells and the effect was only marginally affected by the AhR inhibitor CH223191 (preliminary data, not shown), corroborating previous results obtained by AhR- 
silencing with siRNA (Mayati et al 2011). Combined exposure to pyrene and $\mathrm{B}[a] \mathrm{P}$, resulted in an intermediate response considerably lower than pyrene alone, but higher than $\mathrm{B}[a] \mathrm{P}$ alone (Fig. 5A). In further agreement with our previous studies (16), pyrene failed to induce CYP1A1/CYP1B1expression in HMEC-1 cells, while $\mathrm{B}[a] \mathrm{P}$ induced a statistically significant increase (Fig. 5B). Furthermore, co-exposure with pyrene attenuated $\mathrm{B}[a] \mathrm{P}$-induced CYP1A1/CYP1B1 expression (Fig. 5B).(32)Thus, pyrene seemed to be a selective agonist of the AhR nongenomic pathway in HMEC-1 cells, causing an AhR-dependent increase in $\left[\mathrm{Ca}^{2+}\right]_{i}$. Moreover, combined exposure to pyrene and $\mathrm{B}[a] \mathrm{P}$ led to a reciprocal suppression of the individual effects, suggesting that the two PAHs may possess comparable affinities for the AhR ligand binding site.

\subsection{Pyrene-induced $\left[\mathrm{Ca}^{2+}\right]_{i}$ increase was attenuated by $\beta$-adrenoreceptors}

Previous studies from our consortium have shown that $\mathrm{B}[a] \mathrm{P}$ induced an $\mathrm{AhR}$-independent increase in $\left[\mathrm{Ca}^{2+}\right]_{i}$ through activation of the $\beta 2$-adrenergic receptor ( $\beta 2 \mathrm{AR}$ ) in HMEC-1 and HEK 293 cells, and that $\mathrm{B}[a] \mathrm{P}$ interacts directly with the binding-pocket of $\beta 2 \mathrm{AR}(26)$. Later we also observed that high doses of 1-nitropyrene $(10 \mu \mathrm{M})$ induced $\mathrm{Ca}^{2+}$-responses in bronchial epithelial BEAS-2B cells through a mechanisms that seemed to depend on $\beta 2 \mathrm{AR}$ (33). Thus, to explore whether pyrene-induced $\left[\mathrm{Ca}^{2+}\right]_{i}$ also could be mediated through $\beta 2 \mathrm{AR}$ we examined $\left[\mathrm{Ca}^{2+}\right]_{i}$ in $\mathrm{HEK}$ wildtype cells $\left(\mathrm{HEK}_{\mathrm{wt}}\right)$ which express low levels of $\beta$-adrenoceptors, and in HEK cells overexpressing either $\beta 1 \mathrm{AR}\left(\mathrm{HEK}_{\beta 1}\right)$ or $\beta 2 \mathrm{AR}\left(\mathrm{HEK}_{\beta 2}\right)$. Pyrene induced a strong increase in $\left[\mathrm{Ca}^{2+}\right]_{i}$ in $\mathrm{HEK}_{\mathrm{wt}}$ (Fig. 6). Overexpression of $\beta 1 \mathrm{AR}$ lead to an approximately $50 \%$ reduction in pyrene-induced $\left[\mathrm{Ca}^{2+}\right]_{i}$, compared to $\mathrm{HEK}_{\mathrm{wt}}$, while overexpression of $\beta 2 \mathrm{AR}$ almost completely abolished the pyrene-induced $\left[\mathrm{Ca}^{2+}\right]_{i}$ response (Fig. 6). Furthermore, pre-incubation with the selective $\beta 2 \mathrm{AR}$-antagonist ICI-118,551 appeared to increase pyrene-induced $\left[\mathrm{Ca}^{2+}\right]_{i}$ response in $\mathrm{HEK}_{\beta 2}$ to a level comparable to the effects in $\mathrm{HEK}_{\mathrm{wt}}$ (preliminary data, not shown). This shows that pyrene induced $\left[\mathrm{Ca}^{2+}\right]_{i}$ increases through $\beta 2 \mathrm{AR}$-independent 
mechanisms, and that $\beta$-adrenoceptor activity rather supressed the pyrene calcium-responses. Again, this underscores that pyrene differ from $\mathrm{B}[a] \mathrm{P}$ in its mode of action.

\subsection{Pyrene-induced $\left[\mathrm{Ca}^{2+}\right]_{i}$ increase involved store-operated $\mathrm{Ca}^{2+}$ entry}

Next, we explored the mechanisms of pyrene $\mathrm{Ca}^{2+}$ entry. Removing $\mathrm{Ca}^{2+}$ from the exposure medium caused a partial inhibition of the pyrene-induced $\left[\mathrm{Ca}^{2+}\right]_{i}$ response. The initial increase in $\left[\mathrm{Ca}^{2+}\right]_{i}$ was sustained until 5-6 min in absence of extracellular $\mathrm{Ca}^{2+}$, but then gradually levelled-off compared to the response in normal medium, and subsequently decreased from around 15 min (Fig. 7A). This suggests that the initial phase of the response was due to $\mathrm{Ca}^{2+}$-release from intracellular stores, while later phase depended on influx of extracellular $\mathrm{Ca}^{2+}$. SKF 96365 had a similar effect; the initial response was intact, while the late response was partially inhibited (Fig. 8B). SKF 96365 is a storeoperated $\mathrm{Ca}^{2+}$ entry (SOCE) inhibitor that inhibits Stromal interaction molecule 1 (STIM1), but also blocks transient receptor potential cation (TRPC) channels, voltage-gated $\mathrm{Ca}^{2+}$ channels and potassium channels. By comparison, 2APB seemed to inhibit both the initial and late response, probably due to its inhibiting effect on inositol trisphosphate-receptor (IP3R) as well as SOCE and TRP channels (Fig. 7C). Surprisingly, BtP2, a potent blocker of SOCE and calcium release-activated calcium (CRAC) channels, abolished the $\mathrm{Ca}^{2+}$-response completely (Fig 7D). These result indicate that pyrene may trigger $\left[\mathrm{Ca}^{2+}\right]_{i}$ through an IP3R-dependent release from endoplasmic reticulum followed by SOCE activation.

3.7 Pyrene, but not B[a]P, reduced membrane lipid order in the plasma membrane through an AhR-dependent mechanism

It is known that $\mathrm{Ca}^{2+}$-influx can be affected by physico-chemical characteristics of membrane (eg. membrane order which reflect lipid packing depending on membrane fluidity and local lipid environment thus defining membrane microdomains), and PAHs like $\mathrm{B}[a] \mathrm{P}$ have been shown to affect membrane fluidity $(34,35)$. Moreover, alterations in ordered plasma membrane microdomains, 
such as caveolae, can affect calcium influx (36). Thus we wanted to explore the possibility that pyrene affected the membrane microstructure in HMEC-1. Using the membrane order sensitive dye di-4ANEPPDHQ, we observed that HMEC-1 cells exposed for 30 min to pyrene $(1 \mu \mathrm{M})$ decreased global membrane lipid order compared to cells exposed to vehicle control (DMSO) (Fig. 8A and C). By contrast, $\mathrm{B}[a] \mathrm{P}$ did not affect membrane lipid order in the HMEC-1 cells as determined by di-4ANEPPDHQ (Fig. 8A). Furthermore, the pyrene-induced reduction in membrane order was reversed by pre-treatment with $\mathrm{CH} 223191$ (Fig $8 \mathrm{~B}$ and $\mathrm{C}$ ). However, both pyrene and $\mathrm{B}[a] \mathrm{P}$, in a larger extent, induced an AhR-dependent increase in bulk membrane fluidity measured by EPR (Fig. 9). Thus, the pyrene-specific effect observed by di-4-ANEPPDHQ staining did not appear to be due to general alteration of membrane fluidity, but more likely restricted to effects on repartition between ordered and disordered membrane. In total, this indicates that pyrene may have induced an AhR-dependent destabilization of ordered plasma membrane microdomains in HMEC-1 cells. However, both pyrene and $\mathrm{B}[a] \mathrm{P}$ also seemed to elicit more general effects on membrane fluidity through AhR-dependent mechanisms.

\subsection{Cholesterol, a plasma membrane ordering agent, attenuates pyrene-induced $\left[\mathrm{Ca}^{2+}\right]_{i}$ increase.}

To explore if the membrane order- and the $\mathrm{Ca}^{2+}$-responses were linked, we pre-treated HMEC-1 with cholesterol for 30 min prior to pyrene exposure. The addition of cholesterol, which is known to increase membrane lipid order, partially inhibited the pyrene-induced $\left[\mathrm{Ca}^{2+}\right]_{i}$-response (Fig. 10). Of interest, cholesterol treatment appeared to suppress both the initial and prolonged $\left[\mathrm{Ca}^{2+}\right]_{i}$-increase. Thus, it seems that cholesterol interacted with both the initial release from intracellular stores as well as the more secondary $\left[\mathrm{Ca}^{2+}\right]_{i}$-influx through the plasma membrane. This effect could possibly be related to cholesterol-induced changes in membrane lipid order although it should not be excluded that excess of cholesterol may also have influenced the rate of pyrene-diffusion through the cell membrane. 


\section{Discussion}

Our present results show that pyrene acts as an antagonist with regard to AhR-genomic responses, but induced a relatively rapid AhR-dependent increase in $\left[\mathrm{Ca}^{2+}\right]_{i}$ within min after exposure, consistent with activation of AhR nongenomic signaling. In silico molecular modelling confirm that pyrene may dock in the human AhR-PAS-B binding pocket in the antagonist, but not the agonist conformation. The pyrene-induced $\left[\mathrm{Ca}^{2+}\right]_{i}$ increase seemed to be initiated by $\mathrm{Ca}^{2+}$-release from intracellular stores followed by a later phase of extracellular $\mathrm{Ca}^{2+}$-influx. These effects appeared to be closely linked to an AhR-dependent disruption of lipid ordered membrane microdomains. The results show that pyrene induced cellular effects through molecular mechanisms distinctly different from $\mathrm{B}[a] \mathrm{P}$, and suggest that pyrene could act as a selective activator of AhR-nongenomic calcium signaling.

Pyrene exposure did not trigger AhR-regulated gene expression when added alone, but reduced the $\mathrm{B}[a] \mathrm{P}$-induced CYP1A1/CYP1B1expression by $\sim 50 \%$, indicating that pyrene acts as an antagonist of the classical AhR-genomic signaling. In line with this, in silico molecular modelling indicated that pyrene preferentially docks into AhR-PAS-B binding pocket in the antagonist conformation. However, pyrene induced an AhR-dependent $\left[\mathrm{Ca}^{2+}\right]_{i}$-response, further contrasting $\mathrm{B}[a] \mathrm{P} . \mathrm{B}[a] \mathrm{P}$ which has been reported to increase $\left[\mathrm{Ca}^{2+}\right]_{i}$ by an $\mathrm{AhR}$-independent mechanism $(16,26)$, somewhat surprisingly reduced the pyrene induced $\left[\mathrm{Ca}^{2+}\right]_{i}$-response by $\sim 50 \%$. Thus with regard to the AhR nongenomic calcium response, pyrene may be considered as an $\mathrm{AhR}$ agonist and $\mathrm{B}[a] \mathrm{P}$ as the antagonist. These differential and mutually suppressive AhR-mediated effects of pyrene and $\mathrm{B}[a] \mathrm{P}$ are in accordance with the in silico findings discussed below. A possible explanation to the findings is that the two PAHs compete for binding to the PAS-B binding pocket of the human AhR with relatively comparable affinity.

The previously proposed hypothesis regarding AhR function is that the $307-329(\alpha \mathrm{D}-\alpha \mathrm{F})$ segment of the human AhR behaves as a structural switch between an agonist to an antagonist conformation (30). 
Based also on published AhR-HSP90 interaction studies, Bisson and colleagues (30) have suggested that AhR-antagonist binding results in a conformation change that either promotes premature dissociation of HSP90, or causes structural changes that inhibit AhR nuclear translocation. In particular, ligand interaction with residues Phe 47/ Phe 324 and Ile 48/ Ile 325 appear to play a critical role in the disruption of AhR-HSP90 interface (30). Our present results suggest a high probability of contact between residues Phe 47/Phe 324 - Ile 48/Ile 325 of the AhR and the indole and tolylazophenyl groups of GNF-351 and CH223191, respectively. These antagonists are also capable of inhibiting nuclear translocation and/or AhR/Arnt heterodimerization, in vitro $(37,38)$. In the case of pyrene, the number of possible contacts between the ligand and the two residues are not significant. The overall data suggest that pyrene is able to induce a conformational change of the AhR that differs from the one induced upon binding of either a full agonist (TCDD) or a full antagonist (GNF-351). Thus, AhR-nongenomic calcium signaling may not be restricted to classical agonists of the genomic pathway.

Exposing the HMEC-1 cells in calcium-free medium resulted only in an inhibition of the latter part of the $\mathrm{Ca}^{2+}$ response. This indicates that the initial response originated from intracellular stores, most likely due to release of $\mathrm{Ca}^{2+}$ from the endoplasmic reticulum. A similar inhibition-pattern of pyreneinduced $\left[\mathrm{Ca}^{2+}\right]_{i}$, was obtained by use of SKF96365 which inhibits SOCE by interacting with STIM1 and blocks TRPC and voltage gated channels, thus preventing extracellular $\mathrm{Ca}^{2+}$-entry. By contrast, the commonly used IP3R inhibitor 2APB $(39,40)$, also suppressed the initial phase of pyrene-induced $\left[\mathrm{Ca}^{2+}\right]_{i}$ in HMEC-1 cells. This thus further supports that the pyrene-induced $\left[\mathrm{Ca}^{2+}\right]_{i}$ response is initiated by IP3R-mediated release of calcium from endoplasmic reticulum. Notably a high concentration of BTP2 $(10 \mu \mathrm{M})$, a known SOCE-CRAC and TRPC channel inhibitor $(41,42)$, abrogated the entire calcium response. It thus seems that a high dose of BTP2 affects calcium release from ER as well as SOCE-CRAC and TRPCs in our experimental system. Whether this observation 
could be due to off-target effects of the inhibitor remains unclear. Taken together our results indicate that pyrene triggers a rapid and substantial calcium release from intracellular stores, succeeded by an influx of calcium possibly through SOCE-CRAC and TRPC channels.

Changes in membrane microstructure may affect the activity of membrane bound proteins such as ion channels and receptors and may thus modify cell signaling events including calcium responses. Interestingly, pyrene induced an AhR-dependent disruption of lipid ordered membrane microdomains, as observed by use of di-4-ANEPPDHQ-staining. It has recently been suggested that di-4-ANEPPDHQ-staining which correlate with lipid order is less sensitive to membrane fluidity modifications than to cholesterol level changes in the membrane (43). This could explain the lack of correlation with membrane fluidity measurements by EPR. Thus, the pyrene-induced AhR-dependent reduction in $\triangle \mathrm{GP}$ could reflect a disruption in cholesterol-rich microdomains (reduction of their number or lowering their organisation). AhR has been reported to bind directly with caveolin-1 (Cav1) localized in caveolae, cholesterol rich microdomains and invaginations of the plasma membrane, and exposure to the AhR-ligand PCB77 further enhanced the AhR-Cav1 binding in vascular endothelial cells $(44,45)$. AhR-expression also appears to regulate Cav1-localization in ordered microdomains, and that addition of cholesterol may switch the pattern of Cav1 localisation to a AhR-/-phenotype (45). Caveolae function as $\mathrm{Ca}^{2+}$-signaling microdomains regulating SOCE channels, where Cav1 may act by coupling IP3R with TRPC-channels $(36,46)$. It is therefore tempting to speculate that the pyrene-induced effects on $\mathrm{Ca}^{2+}$ signaling and ordered membrane microdomains is related to this association between AhR and Cav1 within the caveolae. In concordance with this, both Cav1 silencing and $\mathrm{Ca}^{2+}$-inhibition appear to attenuate AhR-induced CYP1A1 expression $(44,47)$. Moreover, caveolins also appear to be central in directing the effects of nongenomic estrogen receptor and glucocorticoid receptor signaling by tethering the receptors into 
the caveolae and dictating the downstream cellular responses $(5,48)$. Nongenomic signaling from a range of nuclear receptors may therefore share some common mechanisms.

$\mathrm{B}[a] \mathrm{P}$ has been shown to trigger an AhR-independent calcium response in HMEC-1 and HEK 293 cells mediated through activation of $\beta 2 \mathrm{AR}(26)$. In contrast, the pyrene-induced $\left[\mathrm{Ca}^{2+}\right]_{i}$, was not only AhR-dependent, but also partially suppressed by $\beta 1$ AR-overexpression and almost completely blocked by $\beta 2$ AR-overexpression in HEK293 cells. These results not only fortify the notion that $\mathrm{B}[a] \mathrm{P}$ and pyrene elicit cellular effects through distinctly different mechanisms, but also suggest that $\beta$-adrenoceptors may affect AhR signaling. It has previously been reported that a PAH-mixture containing more than $50 \%$ pyrene impaired $\beta 2 \mathrm{AR}$ function in airway epithelial and smooth muscle cells (49). A mutually suppressive crosstalk between AhR and $\beta$-adrenoceptor signaling may therefore exist. In light of this, it is interesting to note that also $\beta$-adrenoceptors appear to localize in caveolae and interact with caveolins $(50,51)$.

AhR nongenomic $\mathrm{Ca}^{2+}$-signaling has been proposed as a key mechanism regulating proinflammatory effects associated with TCDD poisoning (1). However, $\mathrm{Ca}^{2+}$ is one of the main cellular second messengers and plays a central role in intracellular signal transduction and cell homeostasis as such $(52,53)$. Thus, AhR-mediated changes in $\left[\mathrm{Ca}^{2+}\right]_{i}$ may therefore add explanations to several effects linked to AhR-ligands. For instance, $\left[\mathrm{Ca}^{2+}\right]_{i}$ regulation in endothelial cells is pivotal to vascular signaling pathways, with important implications for regulating blood pressure and flow under physiological as well as pathophysiological conditions $(53) .\left[\mathrm{Ca}^{2+}\right]_{i}$ is also involved in regulation of endothelial permeability (54). Thus, disturbance of normal $\left[\mathrm{Ca}^{2+}\right]_{i}$ in the vascular endothelium could be of importance to the cardiovascular effects associated with exposure to various AhR ligands (5558). Research on PCB-induced activation of nongenomic AhR-responses in the caveolae, have led to the suggestion that these cholesterol-rich microdomains could act as platforms for pro-inflammatory signaling and modulation of the pathology of vascular diseases (57). In contrast to other AhR- 
agonists, pyrene alone appears to have limited impact on AhR-mediated gene expression. However, results from our laboratory show that pyrene may exacerbate pro-inflammatory responses induced by other agents (14). The biological or toxicological implications of this apparent selective activation of AhR nongenomic calcium signaling therefore remains to clarify.

In conclusion, our present results show that pyrene act as an antagonist of the canonical genomic AhR/Arnt/CYP1-pathway, and a selective activator of AhR nongenomic signaling in endothelial cells, triggering a SOCE-mediated increase in $\left[\mathrm{Ca}^{2+}\right]_{i}$ and alterations in plasma membrane microstructure. In silico molecular modelling confirms that pyrene may interact with the PAS-B binding pocket of the human $\mathrm{AhR}$, but suggests that it may induce a conformational change that differs from those induced upon binding of either a full agonist or antagonist. These results support a notion that AhR genomic and nongenomic signaling could be triggered independently and that activation of AhR nongenomic signaling may not be restricted to the classical AhR-agonists.

\section{Acknowledgements}

The work was supported by the Research Council of Norway, through the Environmental Exposures and Health Outcomes-program (grant no. 228143), as well as Rennes Métropole (France) which provided additional travel grants. We also wish to thank Inserm and the Université de Rennes 1 for financial support.

\section{Conflict of interest statement}

The authors have no conflicts of interest.

\section{References}

1. Matsumura F. The significance of the nongenomic pathway in mediating inflammatory signaling of the dioxin-activated Ah receptor to cause toxic effects. Biochem Pharmacol 2009; 77: 608-626.

2. Tian Y, Rabson AB, Gallo MA. Ah receptor and NF-kappaB interactions: mechanisms and physiological implications. Chem Biol Interact 2002; 141: 97-115.

3. Denison MS, Nagy SR. Activation of the aryl hydrocarbon receptor by structurally diverse exogenous and endogenous chemicals. Annu Rev Pharmacol Toxicol 2003; 43: 309-334. 
4. Guyot E, Chevallier A, Barouki R, Coumoul X. The AhR twist: ligand-dependent AhR signaling and pharmaco-toxicological implications. Drug discovery today 2013; 18 : 479-486.

5. Rainville J, Pollard K, Vasudevan N. Membrane-initiated non-genomic signaling by estrogens in the hypothalamus: cross-talk with glucocorticoids with implications for behavior. Frontiers in endocrinology 2015; 6: 18.

6. Moorthy B, Chu C, Carlin DJ. Polycyclic aromatic hydrocarbons: from metabolism to lung cancer. Toxicol Sci 2015; 145: 5-15.

7. Nisbet IC, LaGoy PK. Toxic equivalency factors (TEFs) for polycyclic aromatic hydrocarbons (PAHs). Regulatory toxicology and pharmacology : RTP 1992; 16: 290-300.

8. Bostrom CE, Gerde P, Hanberg A, Jernstrom B, Johansson C, Kyrklund T, Rannug A, Tornqvist M, Victorin K, Westerholm R. Cancer risk assessment, indicators, and guidelines for polycyclic aromatic hydrocarbons in the ambient air. Environ Health Perspect 2002; 110 Suppl 3: 451-488.

9. Liu H, Xu C, Jiang ZY, Gu A. Association of polycyclic aromatic hydrocarbons and asthma among children 6-19 years: NHANES 2001-2008 and NHANES 2011-2012. Respiratory medicine 2016; 110: 20-27.

10. Ochoa-Martinez AC, Ruiz-Vera T, Pruneda-Alvarez LG, Gonzalez-Palomo AK, AlmendarezReyna CI, Perez-Vazquez FJ, Perez-Maldonado IN. Serum adipocyte-fatty acid binding protein (FABP4) levels in women from Mexico exposed to polycyclic aromatic hydrocarbons (PAHs). Environmental science and pollution research international 2017; 24: 1862-1870.

11. Incardona JP, Collier TK, Scholz NL. Defects in cardiac function precede morphological abnormalities in fish embryos exposed to polycyclic aromatic hydrocarbons. Toxicol Appl Pharmacol 2004; 196: 191-205.

12. Incardona JP, Day HL, Collier TK, Scholz NL. Developmental toxicity of 4-ring polycyclic aromatic hydrocarbons in zebrafish is differentially dependent on $\mathrm{AH}$ receptor isoforms and hepatic cytochrome P4501A metabolism. Toxicol Appl Pharmacol 2006; 217: 308-321.

13. Zhang Y, Wang C, Huang L, Chen R, Chen Y, Zuo Z. Low-level pyrene exposure causes cardiac toxicity in zebrafish (Danio rerio) embryos. Aquatic toxicology (Amsterdam, Netherlands) 2012; 114-115: 119-124.

14. Øvrevik J, Refsnes M, Holme JA, Schwarze PE, Lag M. Mechanisms of chemokine responses by polycyclic aromatic hydrocarbons in bronchial epithelial cells: sensitization through toll-like receptor-3 priming. Toxicol Lett 2013; 219: 125-132.

15. Iwanari M, Nakajima M, Kizu R, Hayakawa K, Yokoi T. Induction of CYP1A1, CYP1A2, and CYP1B1 mRNAs by nitropolycyclic aromatic hydrocarbons in various human tissuederived cells: chemical-, cytochrome P450 isoform-, and cell-specific differences. Arch Toxicol 2002; 76: 287-298.

16. Mayati A, Le Ferrec E, Lagadic-Gossmann D, Fardel O. Aryl hydrocarbon receptorindependent up-regulation of intracellular calcium concentration by environmental polycyclic aromatic hydrocarbons in human endothelial HMEC-1 cells. Environ Toxicol 2011.

17. Vondracek J, Pencikova K, Neca J, Ciganek M, Grycova A, Dvorak Z, Machala M. Assessment of the aryl hydrocarbon receptor-mediated activities of polycyclic aromatic hydrocarbons in a human cell-based reporter gene assay. Environ Pollut 2017; 220: 307-316. 
18. Barron MG, Heintz R, Rice SD. Relative potency of PAHs and heterocycles as aryl hydrocarbon receptor agonists in fish. Marine environmental research 2004; 58: 95 100.

19. Elovaara E, Mikkola J, Stockmann-Juvala H, Luukkanen L, Keski-Hynnila H, Kostiainen R, Pasanen M, Pelkonen O, Vainio H. Polycyclic aromatic hydrocarbon (PAH) metabolizing enzyme activities in human lung, and their inducibility by exposure to naphthalene, phenanthrene, pyrene, chrysene, and benzo(a)pyrene as shown in the rat lung and liver. Arch Toxicol 2007; 81: 169-182.

20. Hendon LA, Carlson EA, Manning S, Brouwer M. Molecular and developmental effects of exposure to pyrene in the early life-stages of Cyprinodon variegatus. Comparative biochemistry and physiology Toxicology \& pharmacology : CBP 2008; 147: 205-215.

21. Landvik NE, Gorria M, Arlt VM, Asare N, Solhaug A, Lagadic-Gossmann D, Holme JA. Effects of nitrated-polycyclic aromatic hydrocarbons and diesel exhaust particle extracts on cell signalling related to apoptosis: possible implications for their mutagenic and carcinogenic effects. Toxicology 2007; 231: 159-174.

22. Øvrevik J, Arlt VM, Oya E, Nagy E, Mollerup S, Phillips DH, Lag M, Holme JA. Differential effects of nitro-PAHs and amino-PAHs on cytokine and chemokine responses in human bronchial epithelial BEAS-2B cells. Toxicol Appl Pharmacol 2010; 242: 270-280.

23. Bisson WH, Koch DC, O'Donnell EF, Khalil SM, Kerkvliet NI, Tanguay RL, Abagyan R, Kolluri SK. Modeling of the aryl hydrocarbon receptor (AhR) ligand binding domain and its utility in virtual ligand screening to predict new AhR ligands. Journal of medicinal chemistry 2009; 52: 5635-5641.

24. Flaveny CA, Murray IA, Perdew GH. Differential gene regulation by the human and mouse aryl hydrocarbon receptor. Toxicol Sci 2010; 114: 217-225.

25. Flaveny CA, Murray IA, Chiaro CR, Perdew GH. Ligand selectivity and gene regulation by the human aryl hydrocarbon receptor in transgenic mice. Mol Pharmacol 2009; 75: 1412-1420.

26. Mayati A, Levoin N, Paris H, N'Diaye M, Courtois A, Uriac P, Lagadic-Gossmann D, Fardel O, Le FE. Induction of intracellular calcium concentration by environmental benzo(a)pyrene involves a beta2-adrenergic receptor/adenylyl cyclase/Epac1/inositol 1,4,5-trisphosphate pathway in endothelial cells. J Biol Chem 2012; 287: 4041-4052.

27. Brinchmann BC, Le Ferrec E, Podechard N, Lagadic-Gossmann D, Shoji KF, Penna A, Kukowski K, Kubatova A, Holme JA, Ovrevik J. Lipophilic Chemicals from Diesel Exhaust Particles Trigger Calcium Response in Human Endothelial Cells via Aryl Hydrocarbon Receptor Non-Genomic Signalling. Int J Mol Sci 2018; 19.

28. Owen DM, Rentero C, Magenau A, Abu-Siniyeh A, Gaus K. Quantitative imaging of membrane lipid order in cells and organisms. Nat Protoc 2011; 7: 24-35.

29. Collin A, Hardonniere K, Chevanne M, Vuillemin J, Podechard N, Burel A, Dimanche-Boitrel MT, Lagadic-Gossmann D, Sergent O. Cooperative interaction of benzo[a]pyrene and ethanol on plasma membrane remodeling is responsible for enhanced oxidative stress and cell death in primary rat hepatocytes. Free radical biology \& medicine 2014; 72: 1122.

30. Perkins A, Phillips JL, Kerkvliet NI, Tanguay RL, Perdew GH, Kolluri SK, Bisson WH. A Structural Switch between Agonist and Antagonist Bound Conformations for a LigandOptimized Model of the Human Aryl Hydrocarbon Receptor Ligand Binding Domain. Biology 2014; 3: 645-669. 
31. Totrov MM, Abagyan RA. Derivation of sensitive discrimination potential for virtual ligand screening. . Proceedings of the Third Annual Intl Conf on Comp Mol Biol 312-320 1999: 312-320.

32. Sekine H, Mimura J, Oshima M, Okawa H, Kanno J, Igarashi K, Gonzalez FJ, Ikuta T, Kawajiri K, Fujii-Kuriyama Y. Hypersensitivity of aryl hydrocarbon receptor-deficient mice to lipopolysaccharide-induced septic shock. Mol Cell Biol 2009; 29: 6391-6400.

33. Mayati A, Le FE, Holme JA, Fardel O, Lagadic-Gossmann D, Øvrevik J. Calcium signaling and beta2-adrenergic receptors regulate 1-nitropyrene induced CXCL8 responses in BEAS2B cells. Toxicol in Vitro 2014; 28: 1153-1157.

34. Wiggins P, Phillips R. Membrane-protein interactions in mechanosensitive channels. Biophysical journal 2005; 88: 880-902.

35. Gorria M, Tekpli X, Sergent O, Huc L, Gaboriau F, Rissel M, Chevanne M, Dimanche-Boitrel MT, Lagadic-Gossmann D. Membrane fluidity changes are associated with benzo[a]pyrene-induced apoptosis in F258 cells: protection by exogenous cholesterol. Annals of the New York Academy of Sciences 2006; 1090: 108-112.

36. Pani B, Singh BB. Lipid rafts/caveolae as microdomains of calcium signaling. Cell calcium 2009; 45: 625-633.

37. Smith KJ, Murray IA, Tanos R, Tellew J, Boitano AE, Bisson WH, Kolluri SK, Cooke MP, Perdew GH. Identification of a high-affinity ligand that exhibits complete aryl hydrocarbon receptor antagonism. The Journal of pharmacology and experimental therapeutics 2011; 338: 318-327.

38. Zhao B, Degroot DE, Hayashi A, He G, Denison MS. CH223191 is a ligand-selective antagonist of the Ah (Dioxin) receptor. Toxicol Sci 2010; 117: 393-403.

39. Maruyama T, Kanaji T, Nakade S, Kanno T, Mikoshiba K. 2APB, 2-aminoethoxydiphenyl borate, a membrane-penetrable modulator of Ins(1,4,5)P3-induced Ca2+ release. Journal of biochemistry 1997; 122: 498-505.

40. Saleem H, Tovey SC, Molinski TF, Taylor CW. Interactions of antagonists with subtypes of inositol 1,4,5-trisphosphate (IP3) receptor. Br J Pharmacol 2014; 171: 3298-3312.

41. Zitt C, Strauss B, Schwarz EC, Spaeth N, Rast G, Hatzelmann A, Hoth M. Potent inhibition of $\mathrm{Ca} 2+$ release-activated $\mathrm{Ca} 2+$ channels and T-lymphocyte activation by the pyrazole derivative BTP2. J Biol Chem 2004; 279: 12427-12437.

42. He LP, Hewavitharana T, Soboloff J, Spassova MA, Gill DL. A functional link between storeoperated and TRPC channels revealed by the 3,5-bis(trifluoromethyl)pyrazole derivative, BTP2. J Biol Chem 2005; 280: 10997-11006.

43. Amaro M, Reina F, Hof M, Eggeling C, Sezgin E. Laurdan and Di-4-ANEPPDHQ probe different properties of the membrane. Journal of physics D: Applied physics 2017; 50: 134004.

44. Lim EJ, Majkova Z, Xu S, Bachas L, Arzuaga X, Smart E, Tseng MT, Toborek M, Hennig B. Coplanar polychlorinated biphenyl-induced CYP1A1 is regulated through caveolae signaling in vascular endothelial cells. Chem Biol Interact 2008; 176: 71-78.

45. Rey-Barroso J, Alvarez-Barrientos A, Rico-Leo E, Contador-Troca M, Carvajal-Gonzalez JM, Echarri A, Del Pozo MA, Fernandez-Salguero PM. The Dioxin receptor modulates Caveolin-1 mobilization during directional migration: role of cholesterol. Cell Commun Signal 2014; 12 : 57.

46. Adebiyi A, Narayanan D, Jaggar JH. Caveolin-1 assembles type 1 inositol 1,4,5trisphosphate receptors and canonical transient receptor potential 3 channels into a 
functional signaling complex in arterial smooth muscle cells. J Biol Chem 2011; 286: 4341-4348.

47. Monteiro P, Gilot D, Le Ferrec E, Rauch C, Lagadic-Gossmann D, Fardel O. Dioxin-mediated up-regulation of aryl hydrocarbon receptor target genes is dependent on the calcium/calmodulin/CaMKIalpha pathway. Mol Pharmacol 2008; 73: 769-777.

48. Samarasinghe RA, Di Maio R, Volonte D, Galbiati F, Lewis M, Romero G, DeFranco DB. Nongenomic glucocorticoid receptor action regulates gap junction intercellular communication and neural progenitor cell proliferation. Proceedings of the National Academy of Sciences of the United States of America 2011; 108: 16657-16662.

49. Factor P, Akhmedov AT, McDonald JD, Qu A, Wu J, Jiang H, Dasgupta T, Panettieri RA, Jr., Perera F, Miller RL. Polycyclic aromatic hydrocarbons impair function of beta2adrenergic receptors in airway epithelial and smooth muscle cells. Am J Respir Cell Mol Biol 2011; 45: 1045-1049.

50. Ostrom RS, Insel PA. The evolving role of lipid rafts and caveolae in G protein-coupled receptor signaling: implications for molecular pharmacology. Br J Pharmacol 2004; 143: 235-245.

51. Allen JA, Yu JZ, Dave RH, Bhatnagar A, Roth BL, Rasenick MM. Caveolin-1 and lipid microdomains regulate Gs trafficking and attenuate Gs/adenylyl cyclase signaling. $\mathrm{Mol}$ Pharmacol 2009; 76: 1082-1093.

52. Clapham DE. Calcium signaling. Cell 2007; 131: 1047-1058.

53. Sandow SL, Senadheera S, Grayson TH, Welsh DG, Murphy TV. Calcium and endotheliummediated vasodilator signaling. Adv Exp Med Biol 2012; 740: 811-831.

54. Tiruppathi C, Minshall RD, Paria BC, Vogel SM, Malik AB. Role of Ca2+ signaling in the regulation of endothelial permeability. Vascular pharmacology 2002; 39: 173-185.

55. Savouret JF, Berdeaux A, Casper RF. The aryl hydrocarbon receptor and its xenobiotic ligands: a fundamental trigger for cardiovascular diseases. Nutrition, metabolism, and cardiovascular diseases : NMCD 2003; 13: 104-113.

56. Korashy HM, El-Kadi AO. The role of aryl hydrocarbon receptor in the pathogenesis of cardiovascular diseases. Drug Metab Rev 2006; 38: 411-450.

57. Majkova Z, Toborek M, Hennig B. The role of caveolae in endothelial cell dysfunction with a focus on nutrition and environmental toxicants. Journal of cellular and molecular medicine 2010; 14: 2359-2370.

58. Perkins JT, Petriello MC, Newsome BJ, Hennig B. Polychlorinated biphenyls and links to cardiovascular disease. Environmental science and pollution research international 2016; 23: 2160-2172.

\section{Tables}

Table 1. ICM scores into human AHR-PAS-B in the agonist conformation

\begin{tabular}{|c|c|c|c|c|}
\hline TCDD & $-24 *$ & \multicolumn{3}{|c|}{ Table 2. ICM scores into human AHR-PAS-B in the antagonist conformation } \\
\hline $\mathbf{B}[\mathbf{a}] \mathbf{P}$ & -6.8 & & & \\
\hline CH-223191 & $-5.01 *$ & & & Figure legends \\
\hline GNF-351 & $+*$ & GNF-351 & -35.14 & \\
\hline Pyrene & + & $\begin{array}{l}\text { CH-223191 } \\
\text { Pyrene }\end{array}$ & $\begin{array}{l}-25.73 \\
-19.79\end{array}$ & FIGURE 1. Effe \\
\hline
\end{tabular}

HMEC-1 cells were exposed to pyrene $(1 \mu \mathrm{M})$ or vehicle control (DMSO). The figure displays 
normalized $\left[\mathrm{Ca}^{2+}\right]_{i}$ from continuous recordings (mean) from 0-30 min and graph given the area under the curve (AUC; mean \pm SEM) of independent experiments $(n=3) .\left[\mathrm{Ca}^{2+}\right]_{i}$ was measured and normalized as described in "Materials and Methods". *Statistically significant difference from the vehicle control (DMSO).

FIGURE 2. Role of AhR in pyrene-induced $\left[\mathbf{C a}^{2+}\right]_{i}$. A: HMEC-1 cells exposed to pyrene $(1 \mu \mathrm{M})$ in presence or absence of the AhR-inhibitor CH223191 (1 $\mu \mathrm{M})$. B: HMEC-1 were transfected with AhR specific SiRNA (SiAhR) or non-target control siRNA (SiNT), and exposed to pyrene $(1 \mu \mathrm{M})$. C: HEK 293 cells were exposed to pyrene $(1 \mu \mathrm{M})$ in presence or absence of $\mathrm{CH} 223191(1 \mu \mathrm{M})$. The graphs depict normalized $\left[\mathrm{Ca}^{2+}\right]_{i}$ from continuous recordings (mean) from 0-30 min and the area under the curve $\left(A U C ;\right.$ mean \pm SEM) of independent experiments $(\mathrm{n}=3-4)$. $\left[\mathrm{Ca}^{2+}\right]_{i}$ was measured and normalized as described in "Materials and Methods". Measurements were started three min before exposure. *Statistically significant effect of the inhibitor.

FIGURE 3. In silico modelling of ligand docking in the AhR PAS-B agonist conformation. Docking pose of TCDD (A) and B[a]P (B) into human AHR-PAS-B binding pocket in the agonist conformation; the ligands are displayed as sticks and coloured by atom type, with carbon atoms in magenta $(\mathrm{TCDD})$ and orange $(\mathrm{B}[\mathrm{a}] \mathrm{P})$; residues are displayed as sticks and coloured by atom type with carbon atoms in green (ICM Molsoft).

FIGURE 4. In silico modelling of ligand docking in the AhR PAS-B antagonist conformation. Docking pose and 2D ligand-receptor interaction diagram of GNF-351 (A), CH223191 (B) and Pyrene (C) into human AHR-PAS-B binding pocket in the antagonist conformation; the ligands are displayed as sticks and colored by atom type, with carbon atoms in magenta (GNF-351), orange (CH223191) and cyan (Pyrene). The calculated binding pocket volume is coloured in blue. Hydrogen bonds are displayed as grey dashed lines (ICM Molsoft). 
FIGURE 5. Effects of pyrene and $B[a] P$, alone and in combination, on $[\mathrm{Ca} 2+]_{i}$ and CYP1A1/CYP1B1mRNA expression. A: Effects of pyrene $(1 \mu \mathrm{M}), \mathrm{B}[a] \mathrm{P}(1 \mu \mathrm{M})$, alone and in combination, on $\left[\mathrm{Ca}^{2+}\right]_{i}$ in HMEC-1 cells. The graph depicts normalized $\left[\mathrm{Ca}^{2+}\right]_{i}$ from continuous recordings (mean) from 0-15 min of independent experiments $(\mathrm{n}=2)$. B: Effects of $2 \mathrm{~h}$ exposure to pyrene $(1 \mu \mathrm{M})$ and $\mathrm{B}[a] \mathrm{P}(1 \mu \mathrm{M})$, alone and in combination, on CYP1A1 and -1B1 expression (mean \pm SEM), as compared to DMSO-exposed controls (dotted line). The results are expressed as means \pm SEM; $(\mathrm{n}=4)$. Normalized $\left[\mathrm{Ca}^{2+}\right]_{i}$ and CYP1A1/CYP1B1expression were measured as described in "Materials and Methods". *Statistically significant difference from vehicle control (DMSO); \#Statistically significant difference from $\mathrm{B}[a] \mathrm{P}$ alone.

FIGURE 6. Role of $\boldsymbol{\beta}$-adrenoceptors in pyrene-induced $\left[\mathbf{C a}^{2+}\right]_{i}$ HEK293 wild type cells $\left(\mathrm{HEK}_{\mathrm{wt}}\right)$ and HEK 293 cells overexpressing either $\beta 1 \mathrm{AR}\left(\mathrm{HEK}_{\beta 1}\right)$ or $\beta 2 \mathrm{AR}\left(\mathrm{HEK}_{\beta 2}\right)$, were exposed to pyrene $(1 \mu \mathrm{M})$. The graphs depict normalized $\left[\mathrm{Ca}^{2+}\right]_{i}$ from continuous recordings (mean) from 0-30 min and the area under the curve (AUC; mean \pm SEM) of independent experiments $(\mathrm{n}=3)$. $\left[\mathrm{Ca}^{2+}\right]_{i}$ was measured and normalized as described in "Materials and Methods" Measurements were started three min before exposure. * Significantly different from pyrene-exposed $\mathrm{HEK}_{\mathrm{wt}}$.

FIGURE 7. Mechanisms of pyrene-induced $\left[\mathrm{Ca}^{2+}\right]_{i}$ increase. Three min after measurements were started cells were exposed to pyrene $(1 \mu \mathrm{M})$. Cells were incubated in medium without $\mathrm{Ca}^{2+}(\mathrm{A})$ or with the following inhibitors SKF $10 \mu \mathrm{M}$ (B), 2APB $50 \mu \mathrm{M}$ (C) or BtP2 $10 \mu \mathrm{M}$ (D) for 30 min prior to exposure to pyrene. $\left[\mathrm{Ca}^{2+}\right]_{\mathrm{i}}$ level measured by normalized ratio of the Fura-2-AM probe during exposure is presented as graph and the area under the curve (AUC) 0-30 min, as mean and mean \pm SEM ( $n=3)$, respectively. *Statistically significant effect of inhibitor.

FIGURE 8. Effects of pyrene and $\mathrm{B}[a] \mathrm{P}$ on membrane lipid order and membrane fluidity in HMEC-1. A: Cells were exposed to pyrene $(1 \mu \mathrm{M})$ or $\mathrm{B}[a] \mathrm{P}(1 \mu \mathrm{M})$ for 30 min before measuring membrane lipid order with the fluorescence dye di-4-ANEPPDHQ. B: Cells were pre-incubated with 
$\mathrm{CH} 223191(1 \mu \mathrm{M})$ for 30 min prior to pyrene $(1 \mu \mathrm{M})$ exposure. C: Representative confocal images of HMEC-1 cells stained with di-4-ANEPPDHQ. Graphs A and B depict mean \pm SEM of technical replicates from 3-5 independent experiments. *Statistically significant difference from vehicle control (DMSO); ${ }^{\circledR}$ Statistically significant difference from pyrene; \#Statistically significant effect of inhibitor.

FIGURE 9. Effects of pyrene and B[a]P on membrane fluidity in HMEC-1. Cells were exposed for 30 min to pyrene $(1 \mu \mathrm{M})$ or $\mathrm{B}[a] \mathrm{P}(1 \mu \mathrm{M})$ alone or in combination with $\mathrm{CH} 223191$ pre-treatment before measuring membrane fluidity by EPR as described in "Materials and Methods". The graph depicts mean \pm SEM of at least 3 independent experiments. *Statistically significant difference from vehicle control (DMSO); ${ }^{\S}$ Statistically significant difference from pyrene; ${ }^{\#}$ Statistically significant effect of inhibitor.

FIGURE 10. Pyrene-induced $\left[\mathrm{Ca}^{2+}\right]_{\mathbf{i}}$ was inhibited by cholesterol in HMEC-1. Three min after measurements were started, cells were exposed to pyrene $(1 \mu \mathrm{M})$. Cholesterol $(15 \mu \mathrm{g} / \mathrm{mL})$ was added 30 min prior to exposure. $\left[\mathrm{Ca}^{2+}\right]_{\mathrm{i}}$ level measured by normalized ratio of the Fura-2-AM probe during exposure is presented as graph and the area under the curve (AUC) 0-30 min, as mean and mean \pm $\operatorname{SEM}(\mathrm{n}=3)$, respectively. *Statistically significant effect of inhibitor. 


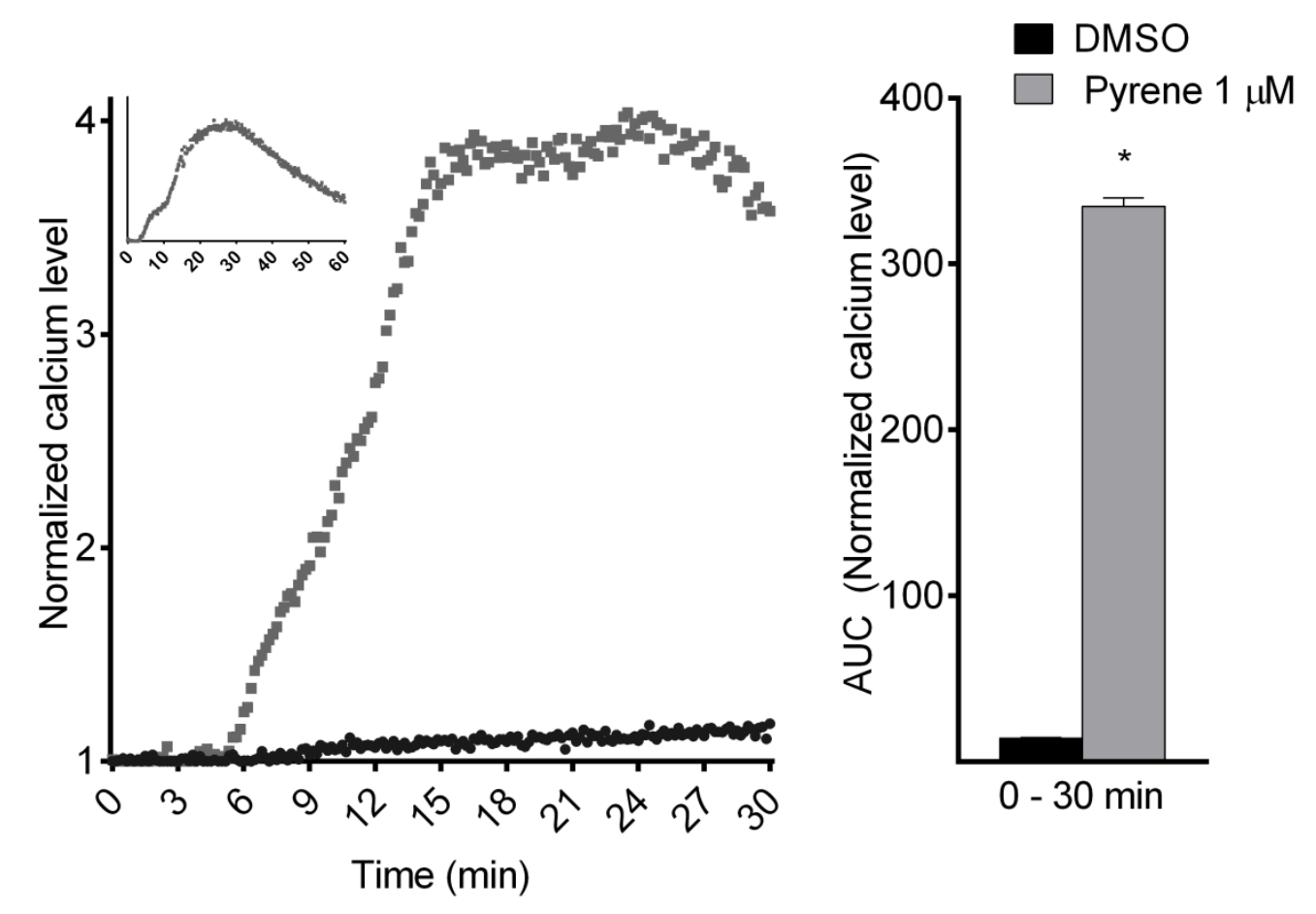



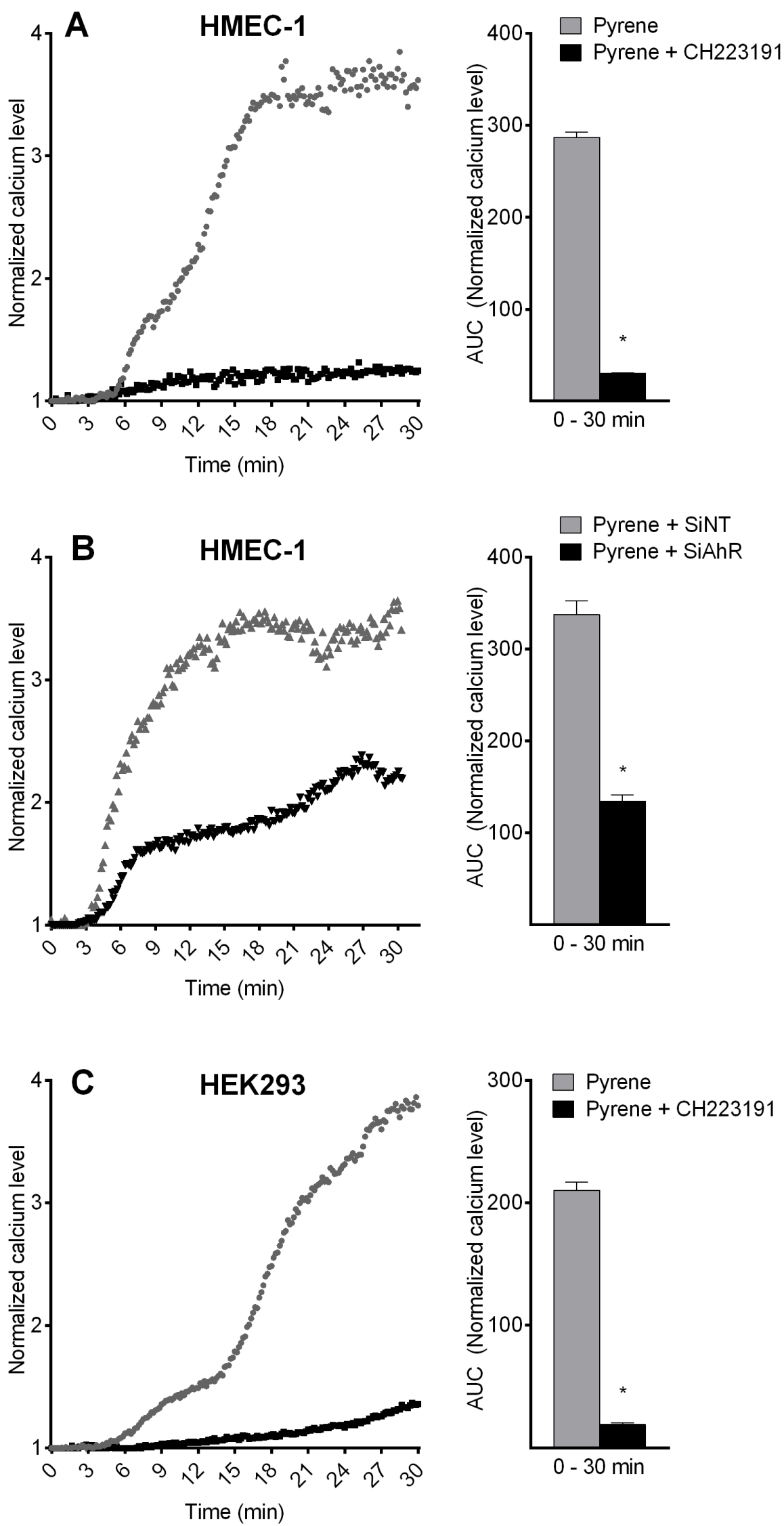


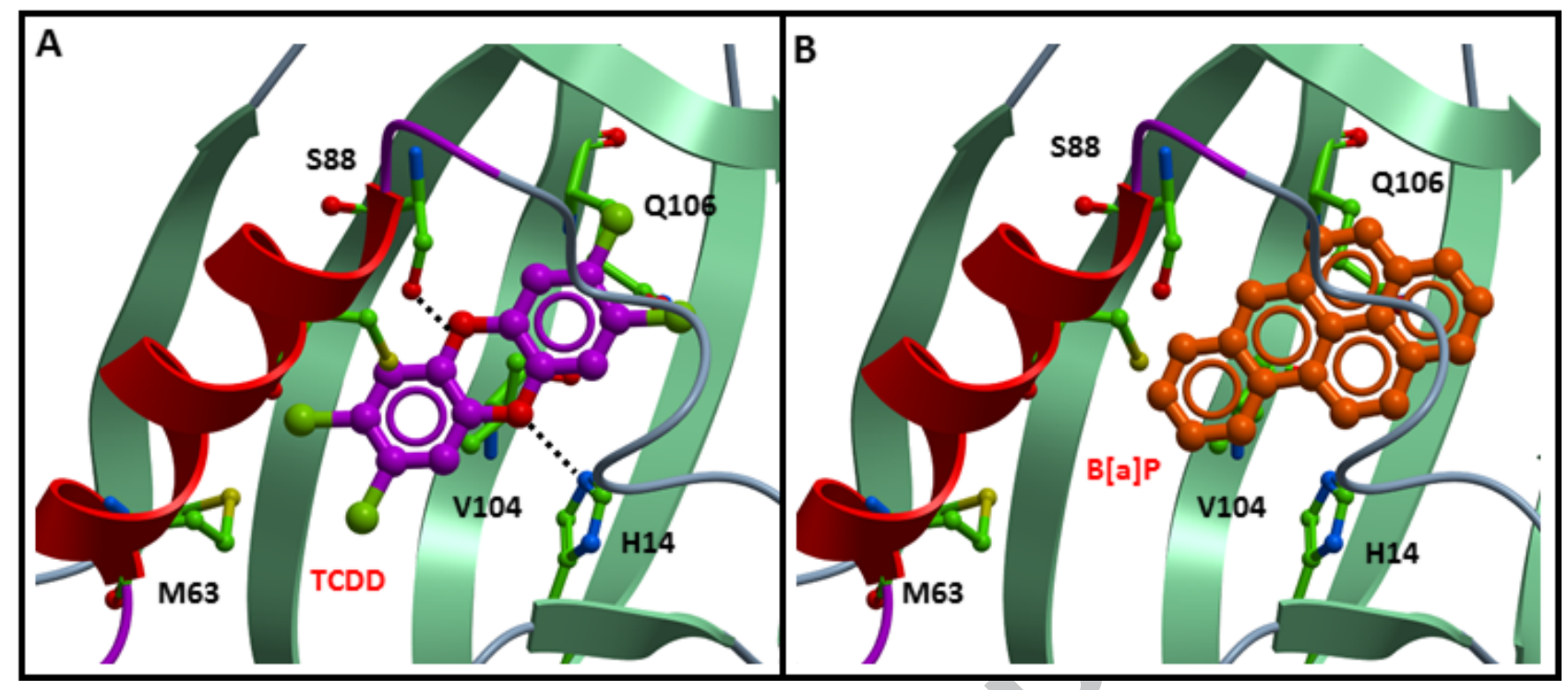




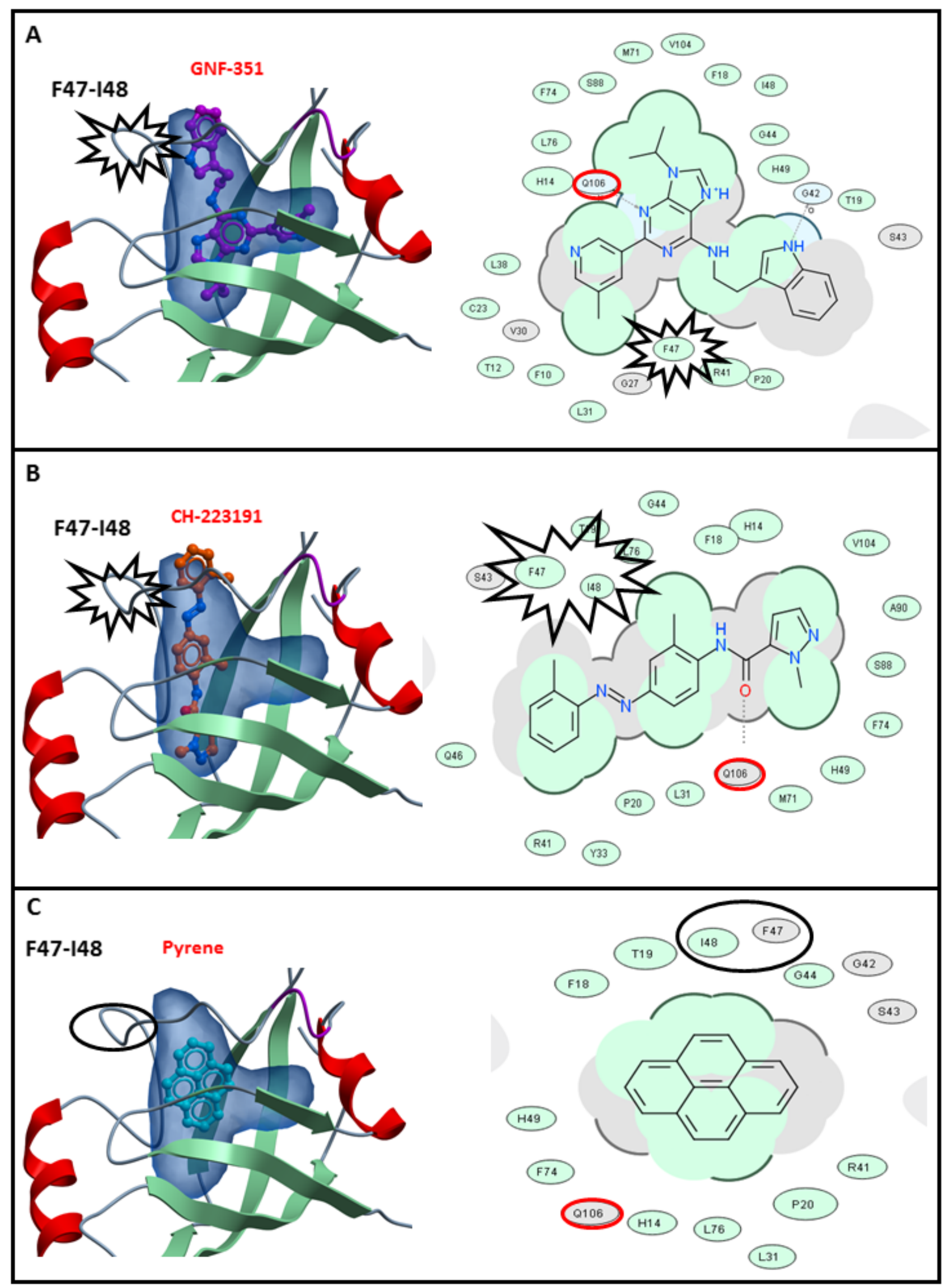


A

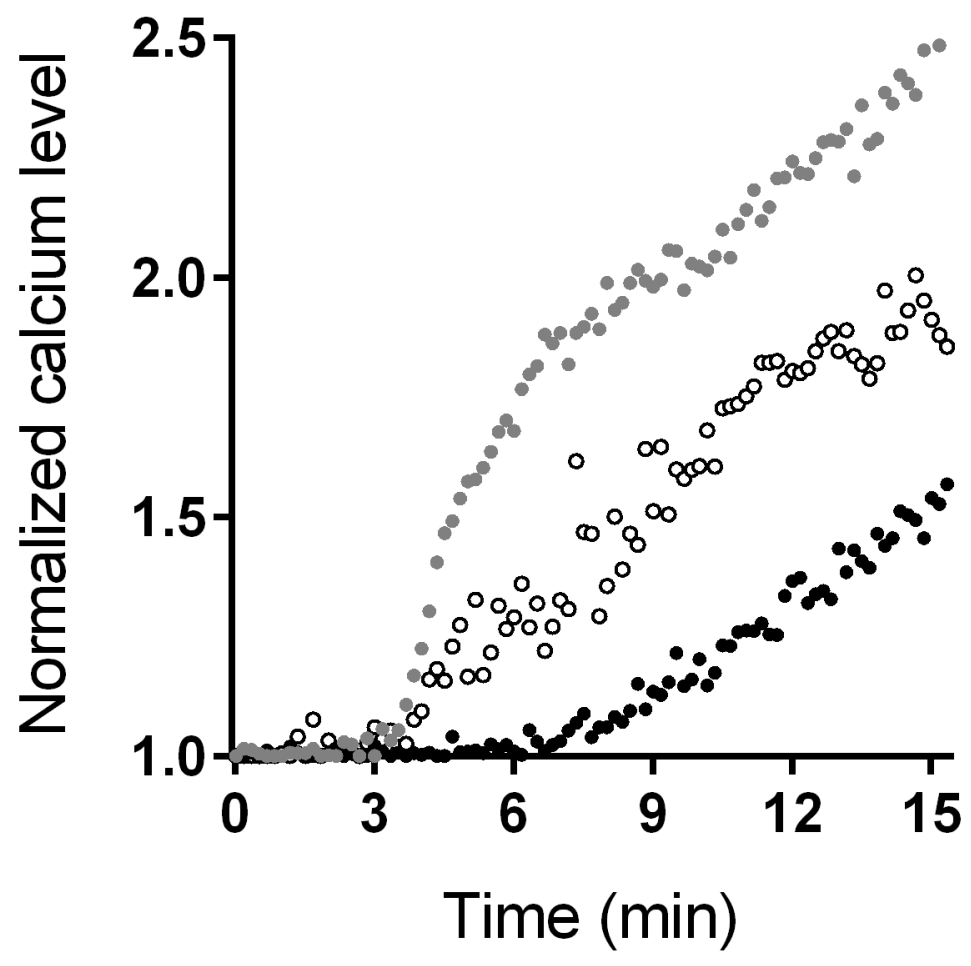

B

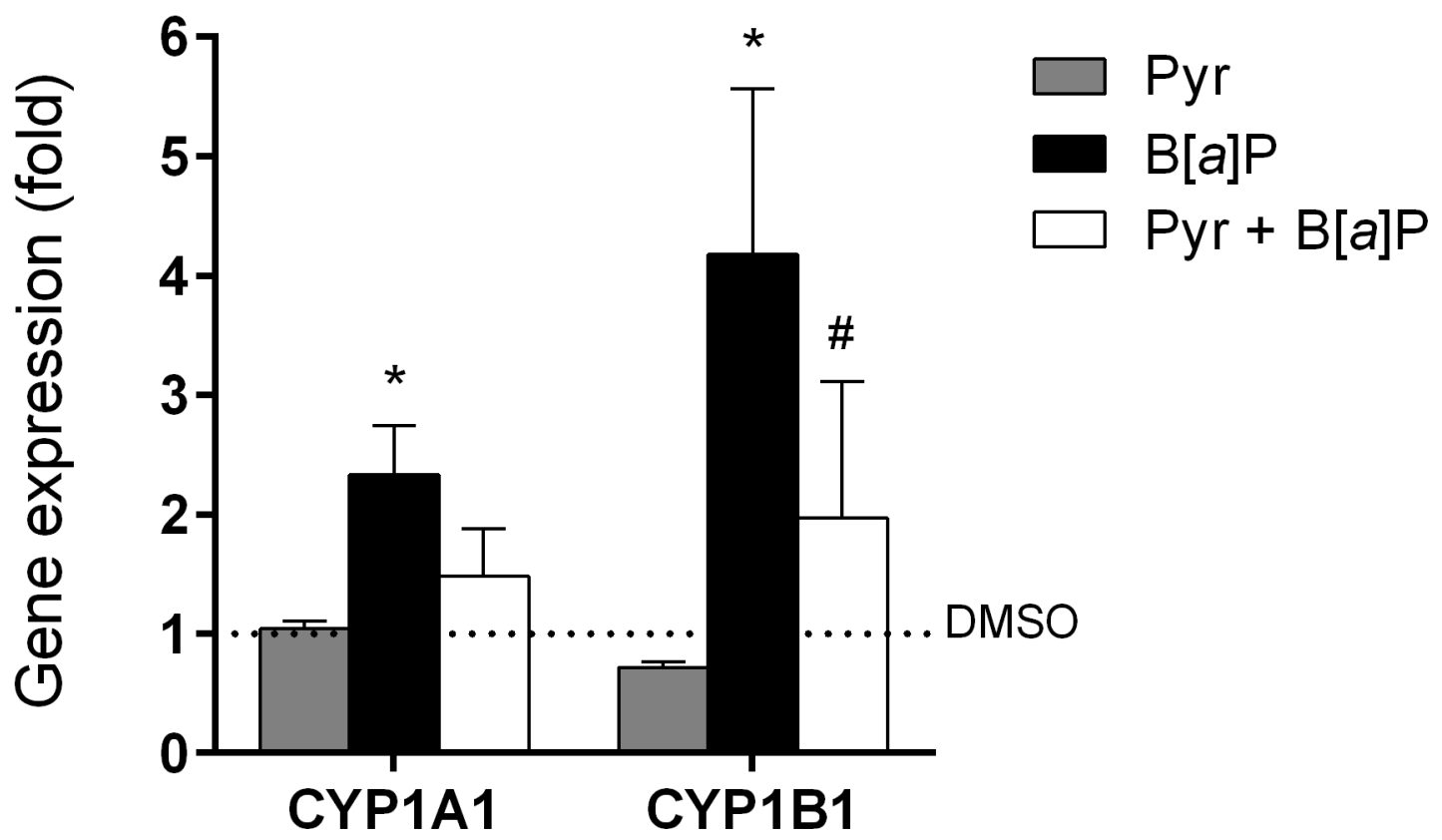



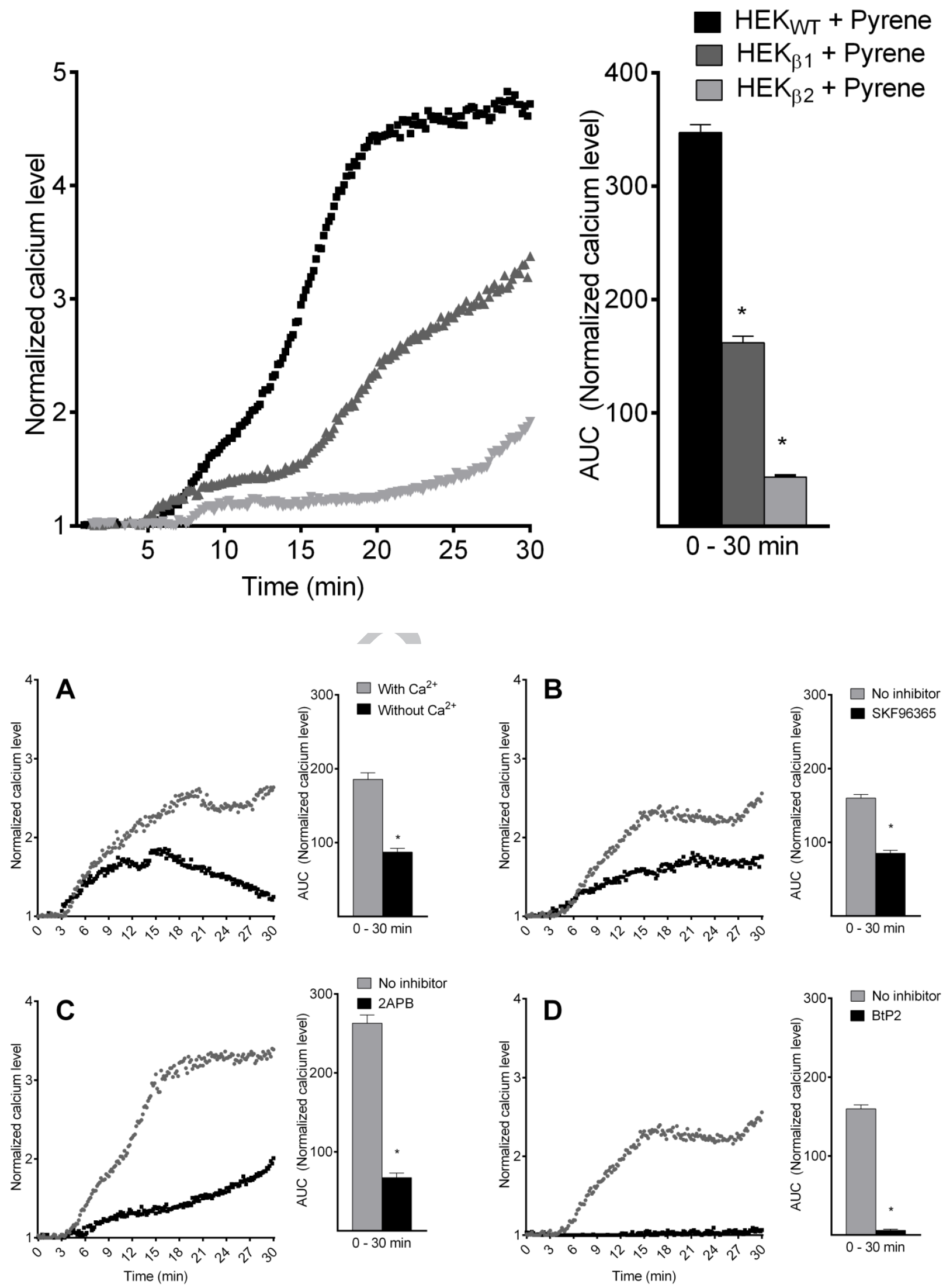
A

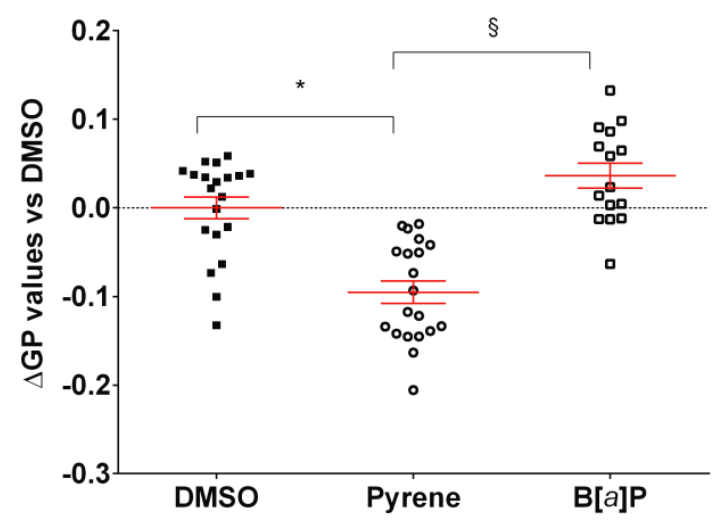

C
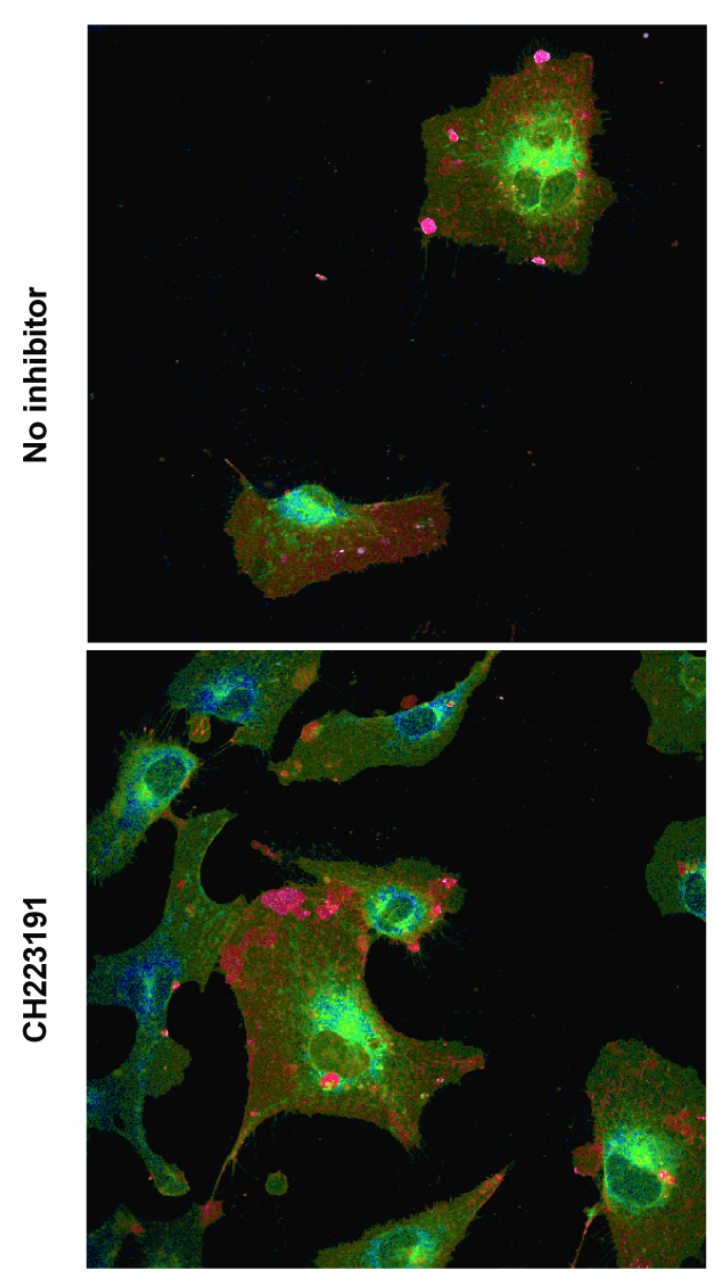

B

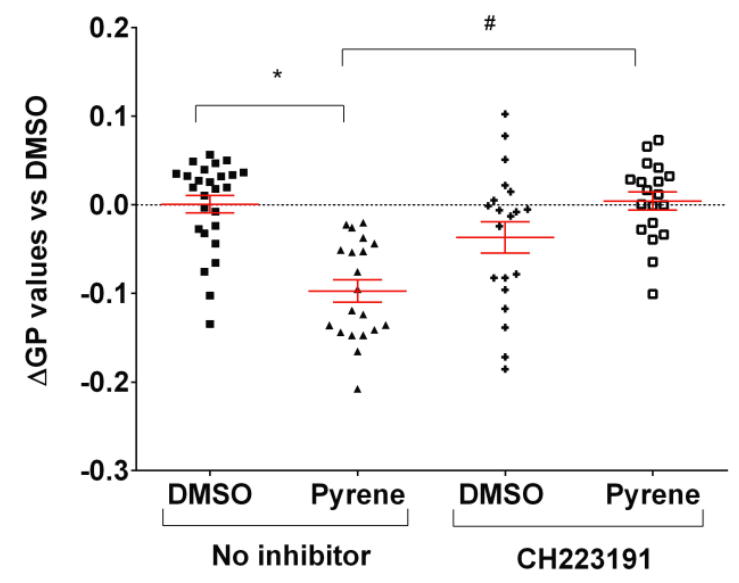

Pyrene

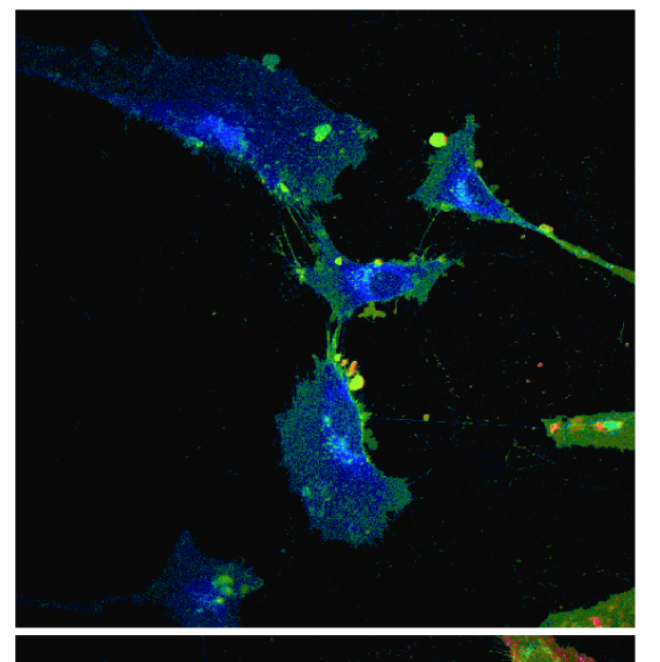

GP
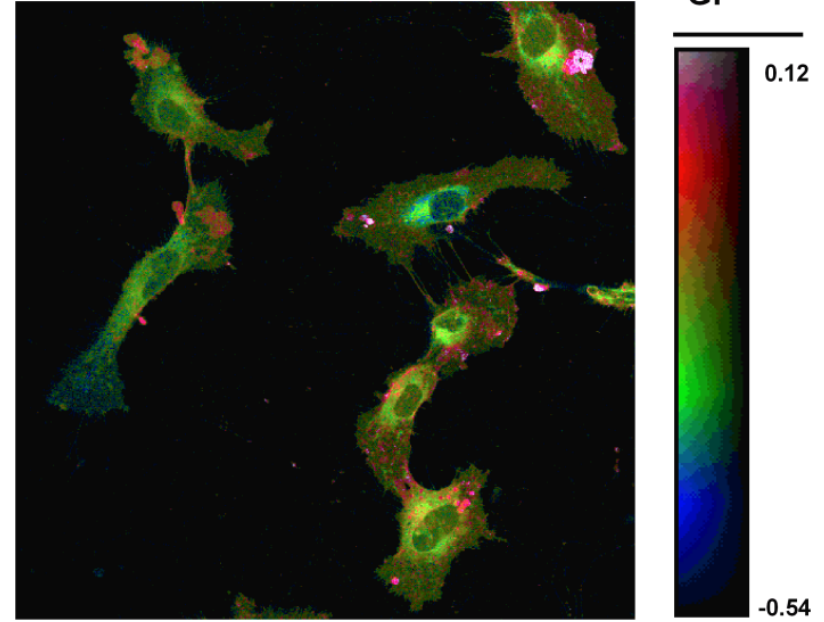

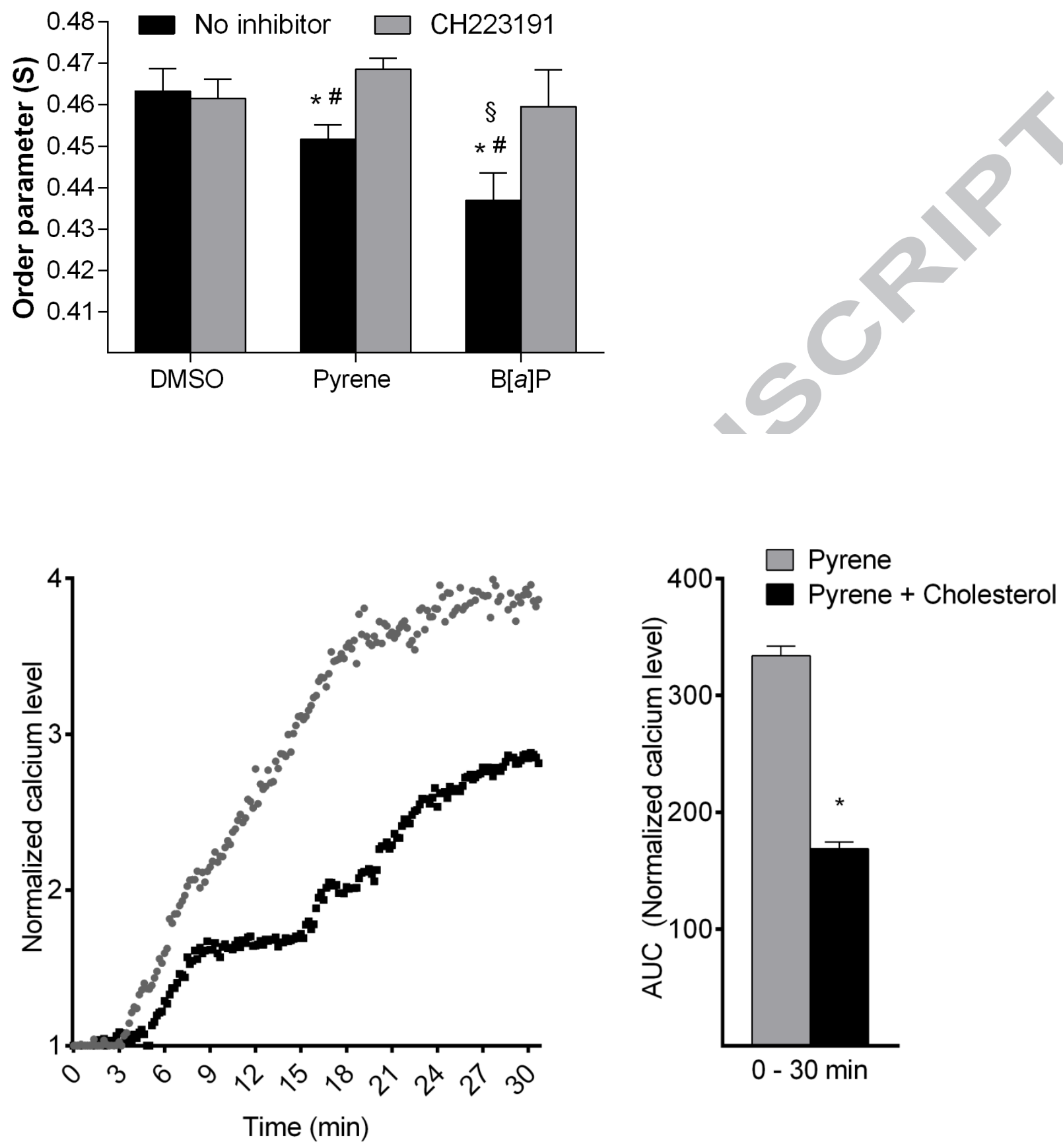
Pyrene antagonize the canonical AhR-genomic pathway and agonize AhR nongenomic calcium signaling

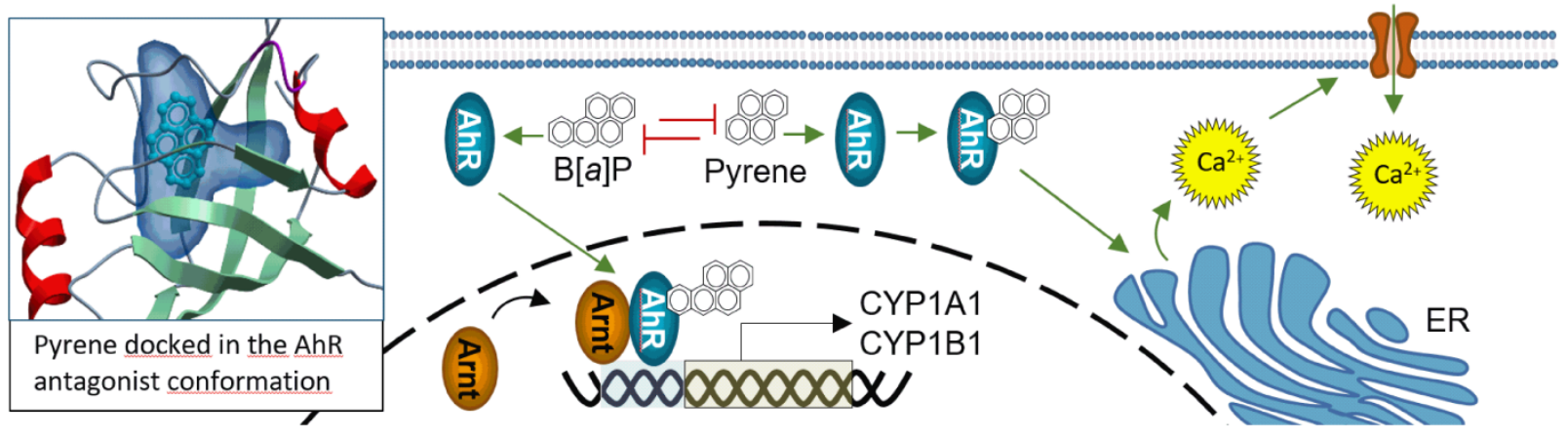

